\title{
Comparison of Cenozoic surface uplift and glacial-interglacial cycles on Himalaya-Tibet paleo-climate: Insights from a regional climate model
}

* Corresponding author:

${ }^{1}$ Institute of Geography and Geology, University of Würzburg, Germany

2 now at: Deutscher Wetterdienst, Offenbach, Germany

${ }^{3}$ Department of Geosciences, University of Tübingen, Germany

${ }^{4}$ now at: Institute of Geography and Geology, Univ. of Würzburg, Germany

Institute of Geography and Geology

University of Würzburg

Am Hubland

97070 Würzburg, Germany

Tel.: +499313184688

Fax: +49 9313185544

heiko.paeth@uni-wuerzburg.de

Heiko Paeth ${ }^{1 *}$

Christian Steger ${ }^{1,2}$

Jingmin $\mathrm{Li}^{3,4}$

Sebastian G. Mutz ${ }^{3}$

Todd A. Ehlers ${ }^{3}$ 


\section{Abstract}

Assessing paleo-climatic changes across the Tibetan Plateau and the underlying driving mechanisms provides insights for the natural variability in the Earth's climate system in response to tectonic processes and global climate change. In this study, we use a high-resolution regional climate model to investigate various episodes of distinct climate states over the Tibetan Plateau region during the Cenozoic rise of the Plateau and Quaternary glacial/interglacial cycles. The main objective is to compare climate changes during the Miocene-Pliocene uplift period with climate anomalies during the last glacial maximum and the mid-Holocene optimum, based on a consistent modeling

54 framework.

Reduced plateau elevation leads to regionally differentiated patterns of higher temperature and lower precipitation amount on the plateau itself, whereas surrounding regions are subject to colder conditions. In particular, Central Asia receives much more precipitation prior to the uplift, mainly due to a shift of the stationary wave train over Eurasia. Cluster analysis indicates that the continental-desert type climate, which is widespread over Central Asia today, appears with the Tibetan Plateau reaching $50 \%$ of its present-day elevation.

The mid-Holocene is characterized by slightly colder temperatures, and the last glacial maximum by considerably colder conditions over most of central and southern Asia. Precipitation anomalies during these episodes are less pronounced and spatially heterogeneous over the Tibetan Plateau. The simulated changes are in good agreement with available paleo-climatic reconstructions from proxy data. The presentday climate classification is only slightly sensitive to the changed boundary conditions in the Quaternary Quaternary. It is shown that in some regions of the Tibetan Plateau 
Clim. Past Discuss., https://doi.org/10.5194/cp-2017-111

Manuscript under review for journal Clim. Past

Discussion started: 17 October 2017

(c) Author(s) 2017. CC BY 4.0 License.

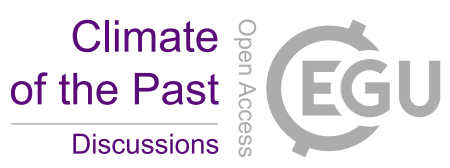

(c) (1)

69 the climate anomalies during the Quaternary Quaternary have been as strong as the

70 changes occurring during the uplift period.

71

72 Keywords: Tibetan Plateau, dynamical downscaling, paleo-climate, surface uplift,

73 Last Glacial Maximum, mid-Holocene

74 


\section{Introduction}

The Tibetan Plateau (TP) is the highest and largest modern elevated plateau and a primary feature of Earth's climate system. Over the last millions of years it has undergone remarkable climate changes, especially during the Miocene-Pliocene uplift period (Clift and Plumb 2008, Mielke et al. 2013, Clift et al. 2014) and in the interplay of glacial and interglacial epochs (Braconnot et al. 2012, Ruddiman 2014). The TP represents a dominant driver of climate variability all around the globe (Molnar et al. 2005). In particular, the thermodynamic and mechanical effect of the TP on the strength, spatial extent and seasonal evolution of the South and East Asian monsoon systems makes it an outstanding factor for low-frequency climate variations (Molnar and Rajagopalan 2012, Park et al. 2012, Tang et al. 2013a). The TP is also a key region of investigation for the current debate on anthropogenic climate change. Climate reconstructions and meteorological data attest tremendous warming rates and record high temperatures during recent decades to the TP region (Guo and Wang 2012, Guangliang et al. 2013) and climate model projections identify one of the hot spots of future climate change in the mountainous areas of Central Asia (Yang et al. 2012, IPCC 2013, Mannig et al. 2013).

The assessment of the anthropogenic interference with climate and its relevance for ecosystems and society requires that the magnitude of natural climate variations and their underlying mechanisms are well understood (e.g. Ruddiman 2014). Given this, this study is dedicated to several outstanding paleo-climatic episodes that we compare in a consistent modeling framework. A number of sensitivity studies with a highresolution regional climate model (RCM) are presented to simulate climate equilibrium states: (1) during different stages of surface uplift of the TP, (2) during the last glacial 
maximum (LGM), and (3) during the mid-Holocene $(\mathrm{MH})$ climate optimum. These episodes have been identified as major time slices of paleo-climatic variability worldwide and in the TP region, in particular (e.g. Braconnot et al. 2012, Mielke et al. 2013, Clift et al. 2014, Ruddiman 2014). In this study, we complement previous work with a focus on three objectives. The first objective of our study addresses the former hypothesis from Prell and Kutzbach (1992), suggesting that glacial versus interglacial boundary conditions during the Quaternary can produce climate anomalies across the TP that are in the same order of magnitude as during Cenozoic (last $\sim 55 \mathrm{Ma}$ ) surface uplift. For this purpose, we compare these different episodes for the first time by means of state-of-the-art climate models using a coherent experimental design.

The second objective pertains to the generation of high-resolution patterns of paleoclimate for the TP and surrounding regions. Typically, paleo-climatic episodes are derived from the interpretation of proxy-data based on tree rings, sedimentary archives, and stable isotope methods (Bartlein et al. 2011, Grießinger et al. 2011, Bershaw et al. 2012, Mischke et al. 2013, Saraswat et al. 2013). Here, we produce simulated climate equilibrium states, prescribing the specific boundary conditions for the various paleoclimatic episodes, which serve as a theoretical basis and benchmark for the interpretation of proxy-data. In addition, some episodes during the early uplift period are addressed where proxy-data are rarely available (Clift and Plumb 2008).

120 Our third objective aims at improving the spatiotemporal representation of paleoclimate across Asia and the TP by relying on a high-resolution RCM. 


\section{Background and previous related work}

126

The effect of the TP uplift on local and regional climate, with particular focus on the Indian summer monsoon, was investigated in earlier work (Hahn and Manabe 1975), revealing the general relationship between uplift and cooling and drying on the TP as well as a strengthening of the South and East Asian monsoons (cf. Kutzbach et al. 1989, 1993). Since then, these basic mechanisms and climate responses have been corroborated by a number of modeling studies with global models using increasing resolution and complexity (e.g. Kitoh et al. 2010, Molnar and Rajagopalan 2012, Park et al. 2012, Wu et al. 2012, Botsyun et al. 2016). Recently, Ma et al. (2014) have demonstrated that the elevation of the Himalaya is more relevant to the changing climate patterns in the Asian monsoon regions than the height of the TP itself. Zhang et al. (2014) have prescribed several regionally differentiated uplift scenarios and draw a rather heterogeneous picture of the climate response to surface uplift. Common to these studies is that they are based on coarse-grid climate models which, probably, cannot account for the finer-scale characteristics of lower atmospheric circulation, precipitation and height-dependent temperature (Braconnot et al. 2012). The deficits of state-of-the-art global climate models for the assessment of present-day climate on the TP have been highlighted by Su et al. (2013). Harrison et al. (2014) have compared paleo-climatological simulations from various climate models with available proxy-data and pointed to a number of substantial biases over Asia. Kitoh et al. (2010) reported some added value when they enhanced the model horizontal resolution of their uplift experiments to $120 \mathrm{~km}$. Finally, work by Botsyun et al. (2016) applied an isotope tracking global general circulation model (LMDZ-iso) to investigate the effect of surface uplift on precipitation $\delta{ }^{18} \mathrm{O}$. They document significant change in the isotopic 
composition of precipitation during surface uplift, and estimate only $\sim 40 \%$ of existing stable isotope based plaleoaltimetry sample locations contain a signal of the plateau surface uplift history. The work of Botsyun et al. (2016) highlights the importance of paleoclimate studies for understanding the tectonic, surface uplift, history of large orogenic plateaus.

As a consequence, RCMs have also been applied to paleo-climatological issues in the TP and Asian monsoon regions. Zheng et al. (2004) have addressed the MH period at a rather low resolution of $120 \mathrm{~km}$. The LGM and $\mathrm{MH}$ have been compared by Ju et al. (2007) who revealed an added value of their RCM at $60 \mathrm{~km}$ resolution with respect to the driving global model. A similar result was obtained by Polanski et al. (2012) at 50 $\mathrm{km}$ resolution for the $\mathrm{MH}$ episode. Liu et al. $(2008 \mathrm{a}, \mathrm{b})$ have used an RCM with a lower resolution of $90 \mathrm{~km}$ but accounted for large number of individual and combined forcings, indicating that changing vegetation, sea level and large-scale atmospheric circulation play a more important role in glacial climate than greenhouse gas concentrations and orbital parameters. In terms of the surface uplift process, Song et al. (2009) have carried out a sequence of experiments with stepwise elevation increase but restricted their simulation period to several months only. More recent RCM simulations with low resolution but spatially differentiated uplift scenarios highlighted the crucial importance of the Himalayan barrier effect for the Indian monsoon and the predominating impact of the TP elevation on the East Asian monsoon system (Tang et al. 2013a), whereas interannual monsoon variability is hardly affected by the uplift stages (Tang et al. 2013b).

In order to meet our main objectives, we pursue a dynamical downscaling approach nesting the RCM REMO at $0.5^{\circ}(\sim 55 \mathrm{~km})$ resolution into the global climate model ECHAM5 (Li et al. 2016a,b; Mutz et al., 2016). For all paleo-climatic episodes the same 
model setup is used in terms of domain, resolution, model physics and driving model, albeit with different boundary conditions for surface uplift magnitude, LGM and MH (see section 2). This approach allows for direct comparison of the resulting climate anomalies with each other. Sensitivity studies over 12 to 40 years are realized which ensures climate equilibrium states of sufficient length for a thorough statistical (cluster) analyses. REMO has been successfully applied and evaluated for climatological issues in Europe (Jacob et al. 2001), Africa (Paeth et al. 2005, 2009), South East Asia (Saeed et al. 2011) and Central Asia (Mannig et al. 2013). In the paleo-climatological context, it has been used in a former version with stable isotopes for uplift scenarios in the Andean region (Insel et al. 2012). Paxian et al. (2016) have recently identified an added value of REMO and other RCMs when it comes to decadal predictability in the West African monsoon system. In the present study, REMO is applied for the first time to a paleo-climatological problem in Asia, assuming that it represents a valuable and efficient tool to generate high-resolution patterns of paleo-climatic episodes to be compared with proxy- data.

190 The subsequent section is dedicated to the description of the model, the experimental design, the validation data and the statistical methods. The results of our analysis are presented in section 4 and discussed in section 5 . The last section comprises the main conclusions and a brief outlook.

\section{Modeling design, data and methods}

The dynamical downscaling is undertaken with the hydrostatic RCM REMO (Jacob 2001). It is nested in the atmospheric global climate model ECHAM5 as atmospheric part of the Max-Planck Institute for Meteorology coupled general circulation model 
ECHAM5/MPI-OM (Jungclaus et al. 2006). For all paleo-climatic episodes REMO is run over the same model domain, extending from $50^{\circ} \mathrm{E}$ to $130^{\circ} \mathrm{E}$ and from the equator to $60^{\circ} \mathrm{N}$ (see Fig. 1). In addition, the same horizontal and vertical resolution is used, amounting to $0.5^{\circ}$ and 27 levels, respectively. The current REMO version is based on the improved land surface scheme from Hagemann and Dümenil (2003) and has been successfully employed in various regions of the globe (e.g. Paeth et al. 2009, Saeed et al. 2011, Insel et al. 2012, Mannig et al. 2013). The REMO setup used here has been extensively evaluated by means of a number of sensitivity studies. Basically two types of experiments have been performed which are described below.

The first type of REMO experiments addresses the uplift process of the TP. For this purpose, the RCM in $0.5^{\circ}$ resolution is nested into AMIP-type global simulations with ECHAM5 using a horizontal spectral resolution of T63 $\left(\sim 1.875^{\circ}\right), 19$ vertical levels and observed sea surface temperature and sea ice data from GISST (Rayner et al. 1996). The uplift is accounted for by a stepwise approach, setting the model topography in ECHAM5 and REMO to $100 \%, 75 \%, 50 \%, 25 \%$ and $0 \%$ of the present-day elevation. According to current geological knowledge (e.g. Molnar et al. 2005, Mielke et al. 2013, Clift et al. 2014), the topography is modified in the domain indicated by the red line in the top panel of Fig. 2, comprising the TP itself, the Himalaya, the Pamir, the Hindukush, the Tian Shan and the Southeast Asian highlands. In contrast, the Altai region in the northern part of our model domain was built prior to the TP uplift and, hence, is not modified (cf. Wang et al. 2006). In order to avoid an artificial trough in Central Asia, a minimum height of $500 \mathrm{~m}$ above sea level is prescribed when reduced topography falls below this threshold. This is in agreement with Le Pichon et al. (1992) who suggested a base height of at least $500 \mathrm{~m}$ for the TP area prior to plateau uplift in the Cenozoic. Along the borders of the region with modified elevation, the discontinuous transition 
between modified and unmodified topography is smoothed by interpolation. The resulting model topographies for the control run (100\% elevation) and the 4 sensitivity studies with stepwise reduction of elevation are displayed in Fig. 2 . It is obvious that for each simulation a continuous land surface without unnatural cracks and slopes is given. In addition, a part of the present-day relative topography across the TP region is retained. Note that we use a rather idealized uplift scenario without regionally differentiated uplift rates (cf. Tapponnier et al. 2001, Tang et al. 2013a, Zhang et al. 2014) nor a modification of the land-sea mask (cf. Fluteau et al. 1999) in order to facilitate the physical interpretation of the climate response to the stepwise uplift process. The control run with present-day elevation covers the period 1961-2000, the other time slices are also based on 40-year model periods. For validation and statistical analysis the first 10 model years are skipped in order to remove some slight spin-up effects during the first model years, as found in temperature and moisture of the deepest soil layer.

The second type of REMO experiments pertains to the LGM and MH episodes. In this case, REMO is nested in a higher-resolution ECHAM5 version with T106 $\left(\sim 1.125^{\circ}\right)$ and 31 vertical levels (Werner et al. 2011). This ECHAM5 version includes stable isotopes and has been analyzed in terms of $\delta^{18} \mathrm{O}$ trajectories ( $\mathrm{Li}$ et al. 2016a,b) and governing factors of $\delta^{18} \mathrm{O}$ (Mutz et al. 2016). The boundary conditions for the LGM and $\mathrm{MH}$ periods have been prescribed equally in ECHAM5 and REMO. This includes greenhouse gas concentrations, land surface characteristics, land-sea mask due to sea level changes (in ECHAM5), and orbital parameters (cf. Ruddiman 2014). The specific boundary conditions for LGM and MH are described in detail by Dietrich et al. (2013). They are in agreement with the guidelines of the Paleoclimate Modelling Intercomparison Project Phase 3 (PMIP3, Arnold et al. 2009). Oceanic boundary 
conditions and sea ice coverage for present-day, LGM and MH are taken from a coupled ECHO-G model experiment (Lorenz and Lohmann 2004). In REMO, the modified land cover classes are translated into monthly varying seasonal cycles of background surface albedo, fractional vegetation cover and leaf area index in order to account for the seasonal evolution of the Asian monsoon systems in a more appropriate way. Given the modified ECHAM5 resolution and model settings in ECHAM5 and REMO, an additional control run is realized covering the period 19781989. 12-year model periods are also applied to the LGM and MH episodes, retaining the last 10 years for model validation and statistical analysis of climate anomalies. For the validation of the present-day climate simulated by ECHAM5 and REMO, we rely on monthly temperature and precipitation data from the CRU data set, a gridded data product based on station observations over land (Mitchell and Jones 2005), from the NCEP (Kalnay et al. 1996) and ERA40 (Uppala et al. 2005) reanalyses, and from the High Asia Reanalysis (HAR), a regional reanalysis with the RCM WRF at a resolution of $0.3^{\circ}$ covering the period 2000-2012 (Maussion et al. 2014) which represents a benchmark for state-of-the-art high-resolution data sets for the TP region. Satellite-based precipitation products such as TRMM have not been considered due to distinct biases over the Himalaya and TP (cf. Barthi and Singh 2015). The LGM and $\mathrm{MH}$ paleo-climatic episodes are compared with quantitative reconstructions of temperature and precipitation from pollen-based proxy-data available over several $2^{\circ}$ $x 2^{\circ}$ grid boxes across the TP and eastern Asia (Bartlein et al. 2011). This data set is also used as a reference for PMIP3 paleo-simulations.

The statistical significance of climate changes due to the uplift process and to the LGM and $\mathrm{MH}$ boundary conditions, respectively, is assessed by means of a one-way analysis of variance (Wilks 2006), taking the offset of the means due to the changing 
boundary conditions as treatment effect and the year-to-year changes within the

276 simulated time series as internal variability.

277 A special focus of our study is on the TP region and on the question whether climate types have noticeably changed due to the various forcings. Therefore, a classification of the Tibetan climate is carried out by a hierarchical cluster analysis combined with a subsequent non-hierarchical k-means correction approach, dedicated to achieve homogeneous clusters which are sharply distinguishable from each other (cf. Paeth et al. 2005, Wilks 2006, Geng et al. 2014, Netzel and Stepinski 2016). The cluster analysis is applied to the domain indicated by the rectangle in Fig. 1. It is based on seven atmospheric variables, including annual-mean 2 meter temperature, annual precipitation amount, annual temperature range, 10 meter zonal and meridional wind components in January and July. Eight clusters have been found to provide the best result in terms of interpretable and discriminable climate types across the TP and surrounding regions.

\section{Results}

\subsection{Model validation}

A comparison of annual temperature and precipitation averaged over the cluster domain (see Fig. 1) between REMO, ECHAM5 and various observational data sets is depicted in Fig. 3. The validation period is 1978-1989. The respective control run from REMO marks the origin of the graph and all other data sets are indicated as anomalies with respect to this control run. Obviously, the considered gridded data and reanalyses differ substantially. Especially, CRU is much drier in the TP region and NCEP noticeably cooler than ERA40 and HAR. The uncertainty on behalf of the observational 
data is at least as pronounced as the potential bias of the RCM REMO. In fact, REMO is quite close to the ERA40 reanalysis and the HAR data set. Note that the latter certainly represents a benchmark for present-day climate on the TP, but the available data period $2000-2012$ is rather short and does not coincide with the simulation periods of ECHAM5 and REMO. The driving global climate model ECHAM5 is characterized by a strong wet bias on the TP. This bias is considerably reduced by dynamical downscaling and points to a clear added value of REMO compared with ECHAM5. This is in line with the study by Mannig et al. (2013) who have validated REMO simulations driven by ERA40 reanalyses and ECHAM5/MPI-OM coupled climate model simulations over entire Asia and concluded that the RCM performs well over the continent and exhibits an added value with respect to the coarser-grid global climate model.

312 A more detailed validation of REMO in the model domain and version presented here 313 has been conducted in the framework of a $\mathrm{PhD}$ project (unpublished $\mathrm{PhD}$ thesis in 2015 by Christian Steger). It has been demonstrated that REMO is able to reproduce

315 the observed main characteristics of climate on the TP and in surrounding regions. 316 Especially temperature at high-elevation sites is well captured and clusters of distinct climate types agree almost perfectly between REMO, ERA40 and HAR. Therefore, it

318 is assumed that REMO provides a reliable basis to simulate paleo-climatic changes.

\subsection{Surface uplift experiments}

321 The temperature changes associated with the surface uplift of the TP and surrounding 322 mountain areas are illustrated in Fig. 4. As the plateau itself and the Asian monsoon 323 systems are subject to a distinct seasonal regime, results are shown for annual means, 324 winter means (DJF) and summer means (JJA). Indeed, the annual temperature range 
increases from south to north and amounts to more than $40^{\circ} \mathrm{C}$ between winter and summer in Central Asia and in parts of the TP (Fig. 4, top panels). It is also obvious that near-surface temperature is a stringent function of elevation. Thus, reduced elevation leads to higher temperature over the TP, simply due to the thermal stratification of the atmosphere (Fig. 4, panels d-o). The warming amounts to more than $10^{\circ} \mathrm{C}$ in the experiment with $0 \%$ of present-day elevation (with a minimum height of $500 \mathrm{~m}$ on the TP). Interestingly, it is a nonlinear function of reduced topography since the warming exhibits larger magnitudes in the $75 \%$ and $50 \%$ experiments than in the $25 \%$ and $0 \%$ experiments. On the TP itself, warming rates in winter and summer are virtually the same. Central Asia is marked by a slight cooling and the continental desert region north of the TP by a noticeable cooling in both seasons, amounting to more than $7^{\circ} \mathrm{C}$, especially in winter. Later on, this will be explained by precipitation and circulation changes. Over South Asia, reduced elevation implies lower temperature in winter and slightly warmer conditions in summer. While the first effect is associated with enhanced cold air advection from the continent due to the missing barrier of the Himalaya and TP, the latter effect is linked to reduced precipitation amount (see below). Thanks to the high resolution of REMO, the resulting climate change patterns are characterized by numerous regional details such as the basin structure on the northeastern TP, the fine-scale changes in the Tian Shan mountain range and the desert basins in western China.

345 The impact of the stepwise uplift on annual, winter and summer precipitation is 346 portrayed in Fig. 5. In the South and East Asian monsoon regions precipitation is 347 mainly a summer phenomenon, whereas the mid-latitudes in Asia follow a more 348 equalized seasonal regime (Fig. 5, top panels). The precipitation response to reduced 349 elevation is marked by a spatially heterogeneous picture (Fig, 5, panels $d-0$ ). The TP, 
South Asia, eastern China and the southern part of Central Asia exhibit drier conditions. In the monsoon areas this amounts to less than $50 \%$. In Central Asia the relative drying is more important. However, the most striking feature in the precipitation response is simulated over the continental arid regions of western China and northwestern Central Asia. Indeed, precipitation increases by up to $250 \%$, when the plateau height is reduced to $25 \%$. This rises to up to four times more than the present-day climatology in some arid regions and is related to circulation changes (see below). Again, the major changes occur up to a reduction to $25 \%$ of present-day elevation, while the $0 \%$ experiment only increases the precipitation signal on the TP itself. An interesting regional detail is given by the wetter conditions in winter along southeastern India and Southeast Asia, where the missing barrier effect of the Himalaya and TP leads to more relief rainfall from the continental winter monsoon flow.

To assess the importance and statistical significance of temperature and precipitation changes due to the uplift process, a one-way analysis of variance has been applied using pairs of uplift experiments or all uplift experiments at once. The analysis of variance reveals that the stepwise uplift scenario accounts for more than $90 \%$ of total annual temperature variability on the TP (Fig. 6, top panels). This implies that the topographic forcing between the 30-year time slices dominates by far the internal yearto-year fluctuations of temperature within the time slices. This effect is already achieved in the $75 \%$ experiment. In the surrounding regions, the uplift effect is less pronounced, ranging between $20 \%$ and $80 \%$ of explained variance. Nevertheless, the temperature changes are statistically significant in almost the entire model domain. For precipitation the picture is more dispersed and the uplift effect is much less pronounced in the $75 \%$ experiment: Precipitation is characterized by substantially stronger internal variability than temperature (e.g. IPCC 2013) and, hence, the uplift process accounts 
375 for a smaller portion of total variance. Nonetheless, the explained variance reaches up

376 to $90 \%$ in the arid regions of western China, where the uplift comes along with a

377 multiplication of present-day precipitation amount.

378 In the following, the substantial drying of the desert basins of western and northern

379 China during the uplift phase is analyzed in more detail. At first sight, this may be

380 interpreted as an increasing barrier effect of the topography, hindering the moist

381 summer monsoon flow from the northern Indian Ocean to penetrate far into the Asian

382 continent. However, a deeper look on the wind components in various atmospheric

383 levels before and after the uplift reveals that in none of the uplift experiments the

384 monsoon air masses propagate into the arid regions of western China, rather these

385 are characterized by extratropical westerlies independent of the topography (not

386 shown). The clue to the problem is given by changes in the extratropical wave train.

387 Fig. 7 displays the mean position of troughs and ridges in the $500 \mathrm{hPa}$ geopotential height field under present-day conditions (top panel) and the respective changes in the $50 \%$ and $0 \%$ experiments (bottom panels). Currently, long-term mean geopotential height is higher over Central Asia and lower over northeastern Asia, indicating the typical position of ridges and troughs, respectively, in the extratropical Rossby waves. Apparently, reduced elevation of the TP implies a substantial large-scale decrease of geopotential height over Central Asia, leading to more advection of moist air masses at the forefront of the trough which is located exactly over the region where the precipitation increase peaks in northwestern China. This appears to be the key mechanism of how the uplift process in the TP regions affects extratropical climate all around the globe (cf. Molnar et al. 2005).

398 The last aspect addressed from the uplift experiments pertains to the identification of 399 distinct climate types on the TP and adjacent regions and their sensitivity to the uplift 
process. In the high-dimensional climate system, climate types often allow for a more comprehensive interpretation of climate changes than individual grid boxes (e.g. Paeth et al. 2005, Geng et al. 2014, Netzel and Stepinski 2016). Fig. 8 presents a climate classification based on eight clusters derived from the 30-year REMO control run (top panel). The clusters are arranged from warm climates (red) to cold climates (blue). The remaining panels refer to the experiments with reduced elevation, but use the cluster centroids from the control run. Under present-day conditions, the desert Tharr in western India occupies cluster 1 which is characterized by very high temperature and low annual rainfall amount. Northwestern India is marked by cluster 2 with still rather high temperature but more humid conditions. Cluster 3 represents the southern slopes of the Himalaya where climate is cooler but annual precipitation exceeds $3000 \mathrm{~mm} / \mathrm{yr}$. Cluster 4 is characterized by intermediate temperature and very dry conditions and covers the continental deserts with less than $100 \mathrm{~mm}$ of annual precipitation, particularly in the Tarim basin. Cluster 5 extends along the foothills on the northern side of the TP, the Tian Shan and the Pamir as well as over the less arid regions of western China. It denotes a colder and more humid climate than cluster 4 . The southern and eastern part of the TP is given by cluster 6 . Annual mean temperature is below $0^{\circ} \mathrm{C}$ and rainfall exceeds $1500 \mathrm{~mm}$ per year. This cluster denotes those parts of the TP on the wind-ward side that are more influenced by moist air advection from the South Asian summer monsoon. In contrast, cluster 8 stands for the much drier and even colder northern part of the TP. Cluster 7 is rather peculiar: it spreads over those areas of the plateau that are marked by a large number of lakes. In the vicinity of these lakes, REMO simulates a climate that is as cold as the one in cluster 8 but with precipitation totals of up to $2000 \mathrm{~mm} / \mathrm{year}$. Later on, this cluster will be identified as a model artefact. 
The experiments with reduced topography manifest a stepwise shift of these climate types towards a setting where the TP exhibits a much warmer and drier climate. North of the TP, climate switches from the continental desert type to a much colder and more humid type which is confined today to the lee side of the TP. Altogether, the climate classification of the $0 \%$ experiment leads to a pattern which fundamentally differs from the one under present-day conditions, highlighting the tremendous impact of the uplift process on climate types on and around the TP. It is also intriguing that the shift of the clusters mainly takes place when the elevation is reduced to $25 \%$ and $0 \%$ of the current topography.

\subsection{Mid-Holocene and LGM experiments}

The simulated temperature anomalies during the LGM and MH episodes are illustrated in Fig. 9. Again, it is differentiated between annual, winter and summer means. Note that the control run for these time slices is slightly different from the one for the uplift experiment and only 10 years per run are available for analysis because the ECHAM5 simulations used for the lateral boundary conditions have much higher resolution and, thus, have been computationally more expensive. It is obvious that the temperature response during the LGM period is much more pronounced than during the $\mathrm{MH}$ time slice. The LGM exhibits lower temperatures in virtually the entire model domain. The cooling amounts to $3-8^{\circ} \mathrm{C}$ with largest amplitude on the TP.

During the $\mathrm{MH}$, the picture is more heterogeneous and temperature changes do not exceed $3^{\circ} \mathrm{C}$. Most regions undergo slightly colder conditions, except for the extratropical part of Asia in summer. Again, the cooling effect peaks over the TP and, in particular, along the southern foothills of the Himalaya. 
The precipitation response during the LGM and $\mathrm{MH}$ periods is spatially rather incoherent (Fig. 10). During the LGM, drier conditions prevail in most parts of Asia, especially in Central Asia and the Middle East. Higher-elevation sites with southward exposition along the Himalaya, the Pamir, the Tian Shan and the Altai may have experienced more precipitation. The most striking feature, however, is the enormous rainfall increase in winter by more than $100 \%$ over eastern India, Bangladesh and parts of Southeast Asia. This increase during the northeasterly winter monsoon flow is contradictory to the present-day seasonality. We have no reasonable physical explanation for such a process and assume it to be a model artefact, possibly arising from a misrepresentation of the prescribed oceanic boundary conditions in the Bay of Bengal that produces a prominent wet bias inland (cf. Paeth et al. 2005).

The MH episode appears to be subject to slightly more annual precipitation amount in most parts of the model domain, except for Central India and the Middle East. This increase mainly takes place during the summer season, initiated by a stronger monsoon flow in East Asia and more advection of moist air masses by westerlies in the extratropics. The pattern of summer precipitation changes is consistent with the temperature response in Fig. 9: higher temperatures north of the TP provoke a northward shift of the summer monsoon flow with more rainfall along the Himalaya and the TP. Vice versa, higher rainfall in northern India and over the foothills of the Himalaya implies a cooling in these areas.

The analysis of variance demonstrates that the impact of LGM and $\mathrm{MH}$ boundary conditions on temperature and precipitation does not everywhere stand out from internal variability (Fig. 11). During the LGM period, the effect on near-surface temperature is outstanding with more than $90 \%$ of explained variance, especially on the TP, in Central Asia and the Middle East. In contrast, the MH episode comes along 
with a weaker temperature response, which peaks over South and Southeastern Asia.

Only a part of the TP region is significantly affected by the MH boundary conditions. Typically, the forcing accounts for $20 \%$ to $70 \%$ of total temperature variance. For precipitation, the picture is more dispersed: the $\mathrm{MH}$ is barely characterized by a coherent rainfall response pattern and, thus, the changes denoted in Fig. 10 should not be over-interpreted, except for the wetter conditions in the southern and western part of the TP. The LGM only leaves a mark in western and southeastern Asia where precipitation is below present-day totals. However, the explained variance ranges mostly below $50 \%$. In Fig. 12 the simulated annual temperature and precipitation changes during the LGM and $\mathrm{MH}$ episodes are compared with available quantitative reconstructions from pollen-based proxy-data (Bartlein et al. 2011). Note that in contrast to Fig. 10 the precipitation response is expressed in mm per year and not in percentage. The $\mathrm{MH}$ period is much better represented by proxy-data than the LGM (cf. Clift and Plumb 2008, Bartlein et al. 2011). During the LGM episode, there is a good agreement between simulated and reconstructed temperature and precipitation, although this comparison is based on a small number of grid boxes. Colder and drier conditions over China and Central Asia are likewise suggested by REMO and proxy-data. The two neighboring reconstructed pixels over the western Tian Shan with opposite temperature changes obviously reflect a data artefact. Unfortunately, the simulated phenomenon of substantial rainfall increase north of the Bay of Bengal (see Fig, 10) can neither be confirmed nor falsified by proxy-data by reason that they are not available in this region.

497 During the $\mathrm{MH}$, the pattern is more complex: reconstructions indicate a small-scale coexistence of warmer and colder conditions over the TP, China and Central Asia, 
whereas in REMO a slight cooling prevails over most of the model domain. On the part of the reconstructions, the temperature response varies by up to $10^{\circ} \mathrm{C}$, partly with opposite sign, over a distance of some hundreds of kilometers. This reflects a large amount of uncertainty in the proxy-data, while the RCM produces a spatially coherent response pattern. In terms of precipitation, there is a satisfactory agreement between model and reconstructions: wetter conditions prevail over the TP, China and parts of Central Asia.

Finally, Fig. 13 clearly reveals that the spatial distribution of main climate types over the TP and surrounding regions is more or less insensitive to the modified boundary conditions during the LGM and $\mathrm{MH}$ periods. Note that in this case the reference clusters for present-day climate have been derived from a shorter period and, hence, the pattern differs slightly from the one in Fig. 8. Under LGM and MH conditions the climate classification barely changes. This is somewhat contradictory to the simulated temperature and precipitation changes presented in Figs. 9 and 10, especially with respect to the considerably colder conditions during the LGM. The fact that the clusters still remain stationary is a clear indication that the other atmospheric variables entering the cluster analysis - i.e. wind components, annual temperature range and, to a certain extent, precipitation - are hardly affected by the modified boundary conditions during LGM and MH. This is a major difference from the uplift experiments (see Fig. 8).

\subsection{Comparison of episodes}

In the last step of our analysis the annual temperature and precipitation changes under uplift, LGM and MH conditions are directly compared with each other, once as regional means over the entire cluster domain and once as averages over each individual cluster (Fig. 14). In addition, the results from REMO and ECHAM5 are compared with 
each other in order to assess which model type is associated with a higher sensitivity. Over the cluster domain, the strongest temperature and precipitation response is found for the uplift experiments, denoting a noticeably drier and warmer climate on and around the TP (top left panel). There is an offset between ECHAM5 and REMO (cf. Fig., 3) but the response is very similar. In both models, the largest changes occur between the $100 \%, 75 \%$ and $50 \%$ experiments, whereas the uplift from $0 \%$ to the $25 \%$ simulation plays a minor role. The LGM and MH affect the mean climate in the cluster domain to a much lower extent. The response in REMO and ECHAM5 is again similar, with one exception: REMO simulates slightly wetter conditions, mainly due to the outstanding precipitation increase over the southeastern TP (see Fig. 10), while ECHAM5 suggests a drying.

Fig. 14 also indicates that the striking climate changes during the uplift process are mainly performed by clusters $3,6,7$ and 8 . These clusters represent the higherelevation sites and southward slopes of the TP and Himalaya. The changes in cluster 3 and 8 even lie outside the illustrated precipitation and temperature range, respectively, highlighting the enormous drying along the southern slope and warming on the northern TP at reduced elevation. In addition, clusters 4 and 5 experience a substantial precipitation increase in the $25 \%$ and $0 \%$ experiments, suggesting that the continental dry climate north of the TP has not yet existed during the early uplift phase (cf. Fig. 5). This effect is only simulated by REMO at higher spatial resolution. LGM and $\mathrm{MH}$ have mainly affected the clusters $3,4,5$ and 6 . Clusters 4 and 5 are representative of the arid and semi-arid climate types north of the TP. Nonetheless, temperature over the TP (clusters 7 and 8) also decreases considerably under LGM conditions. In most cluster regions around the TP, the climate changes during LGM and $\mathrm{MH}$ range are of the same order of magnitude as during the uplift process. In 
contrast, the TP itself is much more sensitive to the plateau uplift and, hence, stronger signals should be expected in proxy-data for that earlier period.

\section{Discussion}

553

This study provides new insight into prominent Cenozoic and Quaternary paleoclimatic variations in Asia and, more specifically, in the TP region. The comparative validation of the RCM REMO and the driving global climate model ECHAM5 has shown that the higher-resolution model is closer to the available observational data and reanalyses, particularly with respect to precipitation. This is consistent with other studies highlighting the added value of higher-resolution climate models in Asia and other regions of the globe (e.g. Kitoh et al. 2010, Paeth et al. 2011, Mannig et al. 2013, Paxian et al. 2016).

The uplift experiments with stepwise reduction of topography describe a continuous transition towards a warmer and drier climate on the TP when elevation decreases. This general tendency has been found in virtually all uplift experiments since the pioneering work by Hahn and Manabe (1975) and Kutzbach et al. (1989, 1993). Another earlier finding, which we could corroborate with this study, is the fact that the later uplift process has played a more important role for the TP climate and surrounding monsoon systems than the early phase. In our study, the changes are stronger between the $100 \%, 75 \%$ and $50 \%$ experiments than between the $25 \%$ and $0 \%$ simulations. Kitoh et al. (2010) have reported that their 60\% experiment represented a threshold for accelerated climate change. A novel aspect of our modeling design pertains to the high spatial resolution and, at the same time, the relatively long simulation periods for the time slices, which allow for a more sophisticated statistical 
assessment of changes and their significance. A new finding arising from the high resolution of the REMO model concerns the appearance of the continental-desert type of climate that first occurred in the transition from the $25 \%$ to the $50 \%$ experiment. This process is probably related to dynamical changes in the extratropical Rossby wave configuration. The identification of climate types by means of cluster analysis has proven to be an instructive tool to illustrate changes at the scale of regional climates (cf. Geng et al. 2014, Netzel and Stepinski 2016). In fact, it could be shown that the uplift process induces a fundamental rearrangement of present-day climate types on the TP and in surrounding regions, especially to the north. During the LGM period, REMO simulates colder conditions in most regions of Asia with the largest temperature decrease in winter over the TP and in the northernmost part of the model domain along $60^{\circ} \mathrm{N}$. This is in agreement with previous modeling studies (e.g. Liu et al. 2008a,b, Harrison et al. 2014) and reconstructions (e.g. Mischke et al. 2013, Saraswat et al. 2013). The cooling in our model ranges between $3^{\circ} \mathrm{C}$ and $8^{\circ} \mathrm{C}$ on the TP which agrees well with proxy-data from Bartlein et al. (2011). In contrast, other authors have stated that the LGM cooling rate is underestimated by their global (Harrison et al. 2014) and regional (Zheng et al. 2004, Ju et al. 2007) climate models. In terms of precipitation, the pattern is dominated by drier conditions in most of the model domain. However, precipitation amount over the TP itself is mainly unaffected, except for an extensive increase in the southeastern part, which we assign to a model artefact. In general, precipitation changes are strongly superimposed by internal variability within the time slices. Despite the noticeable cooling tendency, the spatial arrangement of climate types during the LGM episode can hardly be distinguished from the present-day situation, mainly because atmospheric circulation is more or less unchanged. 
The temperature effect during the $\mathrm{MH}$ period is minor compared with the other paleoclimatic time slices. A slight cooling of less than $1^{\circ} \mathrm{C}$ prevails over most of Asia. Over the TP and northern India it reaches up to $3^{\circ} \mathrm{C}$. During summer, the extratropical part of the model domain experiences some warming by $1-2^{\circ} \mathrm{C}$. While this minor cooling tendency in REMO is consistent with the majority of temperature reconstructions in central and eastern Asia (cf. Bartlein et al. 2011, Braconnot et al. 2012), it disagrees with former modeling approaches for the $\mathrm{MH}$ period which suggest a slight warming (Zheng et al. 2004, Polanski et al. 2012, Harrison et al. 2014). Concerning precipitation, our model confirms the wetter conditions over the TP, northern India, eastern Asia and northern China as suggested by other authors (e.g. Zheng et al. 2004, Polanski et al. 2012, Saraswat et al. 2013). Yet, the precipitation changes hardly stand out from the internal variability within the $\mathrm{MH}$ time slice. The climate classification during the $\mathrm{MH}$ is also largely congruent with the one under present-day conditions.

The application of a uniform downscaling approach with an RCM using the same model domain, resolution and model physics allows for a direct comparison of climate change signals among all considered time slices, which is unprecedented for uplift, LGM and $\mathrm{MH}$ episodes. Not surprisingly, the uplift process is associated with the largest temperature and precipitation response and shift of climate types, at least on the basis of the entire TP region. These regional-mean changes hardly differ between REMO and ECHAM5. In both models, the uplift mainly affects the high-elevation clusters over the TP. However, the disappearance of the arid climate types north of the TP in the $25 \%$ and $0 \%$ experiments is a feature that only occurs at higher resolution in REMO. Another interesting finding is that at the scale of individual clusters, i.e. regional climates, glacial and, to a lower extent, $\mathrm{MH}$ conditions can provoke climate anomalies in the same order of magnitude as the uplift process. This mainly pertains to the climate 
types in northern India and along the southern slopes of the Himalaya. Thus, the former hypothesis by Prell and Kutzbach (1992) can be supported by our model results.

\section{Conclusions}

628

The main objectives of the present study were to assess and compare paleo-climatic changes in Asia and, especially, in the TP region. For this purpose, we have carried out a series of RCM experiments that are characterized by high spatial resolution and sufficiently long simulation periods to account for the impacts of uplift, LGM and $M H$ boundary conditions on the regional climate and to allow for a comparison with available climate reconstructions from proxy-data. The modeling design was such that a direct comparison of all considered paleo-climatic episodes is ensured.

Our first objective pertained to the former hypothesis by Prell and Kutzbach (1992), suggesting that glacial boundary conditions can produce similar climate changes as the uplift process during the Miocene-Pliocene period. This hypothesis could be confirmed on the basis of regionally confined climate types, especially to the south of the TP. However, at the scale of the entire region of the TP and adjacent areas, climate is clearly more sensitive to the uplift than to Quaternary forcings during the LGM and MH periods.

The second main objective referred to the generation of high-resolution patterns of paleo-climatic states that are suitable for a quantitative comparison with climate reconstructions. For the LGM period, this comparison is successful but based on a very small number of grid boxes. The proxy-data for the $\mathrm{MH}$ episode are more numerous and wide-spread over Asia. However, they exhibit substantial uncertainty, drawing a picture of substantial temperature rise and decrease at neighboring locations. 
In contrast, our model produces patterns of paleo-climatic anomalies that are spatially more coherent and physically consistent. Therefore, we suggest that RCMs are able to provide a valuable theoretical basis for the assessment of paleo-climate and the climatological interpretation of proxy-data.

The third objective aimed at improving the spatiotemporal representation of paleoclimatic episodes in Asia. Indeed, the simulation periods of 12 to 40 years per time slice allowed for a sophisticated statistical analysis of climate changes in order to distinguish between real climate change signals and climate anomalies that do not stand out from internal variability. The horizontal resolution of $0.5^{\circ}$ used in the RCM REMO has proven to add value to the representation of climate across the TP, compared with the driving global climate model. This relates to the model bias in terms of present-day climate, the regional details of simulated climate patterns - especially for the cluster analysis - and some new insights into climate changes north of the TP, i.e. the appearance of the arid climate types in western China when the TP reaches at least $50 \%$ of its present-day elevation.

There is still room for improvement of the model itself, the modified boundary conditions and the number of experiments. First of all, the matrix of paleo-climatic simulations could be extended, accounting for spatially differentiated uplift scenarios (cf. Tapponnier et al. 2001, Tang et al. 2013a, Zhang et al. 2014), modified paleogeography (Fluteau et al. 1999), and a decomposition of forcings during the LGM and MH periods (Liu et al. 2008a,b, Polanski et al. 2012). This would lead to a more comprehensive understanding of the processes leading to paleo-climatic changes but, at the same time, require enormous computing resources beyond the scope of our project. In addition, simulations over several hundreds or thousands of years would help to assess the superposition of time scales of climate fluctuations and changes 
674 arising from internal and external sources of variability, respectively (cf. Lorenz and 675 Lohmann 2004).

676 The RCM REMO has been shown to have a good performance in terms of the prominent features of regional climate in Asia and on the TP. Some systematic biases can still be removed by statistical post-processing (e.g. Paeth 2011). However, a major deficit is the simulation of precipitation over high-elevation lakes on the TP where surface water temperature in winter is substantially overestimated and precipitation amount by far too high. In the future, this problem will be tackled by implementing the lake model FLake (Mironov et al. 2010) in REMO. Some further improvements can be expected when REMO is used in a version that is fully coupled to an ocean model enhancing the physical consistency of the climate simulations (cf. Sein et al. 2015). Recently, Gao et al. (2015) have implemented a more realistic land cover classification in REMO and reported an enhanced skill of the model. Finally, the aspect of model uncertainty must be addressed also for the assessment of paleo-climatic changes, e.g. by running a multi-model ensemble of RCMs nested into different global climate models from the PMIP3 initiative. Combining this with the matrix of more sensitivity studies implies an enormous computational effort that could be achieved in the framework of a potential future paleo-CORDEX initiative.

\section{Acknowledgements}

We thank the ECMWF, the NCAR-NCEP, the Climatic Research Unit and the Department of Climatology at Freie Universität Berlin for providing the ERA40 reanalyses, the NCEP reanalyses, the CRU data set and the High Asian Reanalysis (HAR), respectively. This work was supported by by the German Research Foundation 
Clim. Past Discuss., https://doi.org/10.5194/cp-2017-111

Manuscript under review for journal Clim. Past

Discussion started: 17 October 2017

(c) Author(s) 2017. CC BY 4.0 License.

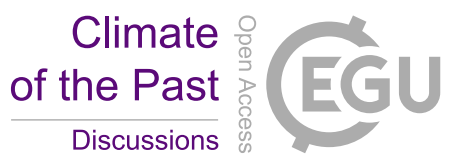

(c) (1)

699 (DFG) grants PA 1194/7 and EH 329/2, and European Research Council (ERC)

700 Consolidator Grant number 615703 to T. Ehlers.

701

702 


\section{References}

704

705

706

Arnold, L., F.-M. Bréon, and S. Brewer (2009), The Earth as an extrasolar planet: the vegetation spectral signature today and during the last Quaternary climatic extrema, Int. J. Astrobiol. 8, 81.

Barthi, V., and C. Singh (2015), Evaluation of error in TRMM 3B42V7 precipitation estimates over the Himalayan region, J. Geophys. Res. 120, 12458-12473.

Bartlein P.J. and 18 co-authors (2011), Pollen-based continental climate reconstructions at 6 and 21 ka: a global synthesis, Climate Dyn. 37, 775-802.

Bershaw, J., S.M. Penny, and C.N. Garzione (2012), Stable isotopes of modern water across the Himalaya and eastern Tibet: Implications for estimates of paleoelevation and paleoclimate, J. Geophys. Res. 117, doi:10.1029/2011JD016132.

Botysun, S., Sepulchre, P., Risi, C., and Y. Donnadieu (2016), Impacts of Tibetan Plateau uplift on atmospheric dynamics and associated precipitation $\delta^{18} \mathrm{O}$, Clim. Past. 12, doi:10.519/cp-12-1401-2016.

Braconnot, P., S.P. Harrison, M. Kageyama, P.J. Bartlein, V. Masson-Delmotte, A. Abe-Ouchi, B. Otto-Bliesner, and Y. Zhao (2012), Evaluation of climate models using Palaeoclimatic data, Nature Climate Change 2, 417-424.

Clift, P.D., and R.A. Plumb (2008), The Asian monsoon: causes, history and effects, Cambridge Univ. Press.

Clift, P.D., R. Tada, and H. Zheng (2014), Monsoon evolution and tectonics-climate linkage in Asia: an introduction, Geol. Soc. London, Special Publ. 342, 1-4.

Dietrich, S., M. Werner, T. Spangehl, and G. Lohmann (2013), Influence of orbital forcing and solar activity on water isotopes in precipitation during the mid- and llate Holocene, Clim. Past 9, 13-26. 
Fluteau, F., G. Ramstein, and J. Besse (1999), Simulating the evolution of the Asian and African monsoons during the past 30 Myr using an atmospheric general circulation model, J. Geophys. Res. 104, 11995-12018.

Gao, Y., S. Weiher, T. Markkanen, J.-P. Pietikänen, H. Gregow, H.M. Henttonen, D. Jacob, and A. Laaksonen (2015), Implementation of the CORINE land use classification in the regional climate model REMO, Boreal Environ. Res. 20, 261282.

Geng, Q., P. Wu, X. Zhao, and Y. Wang (2014), Comparison of classification methods for the division of wet/dry climate regions in Northwest China, Int. J. Climatol. 34, 2163-2174.

Grießinger, J., A. Bräuning, G. Helle, A. Thomas, and G. Schleser (2011), Quaternary Holocene Asian summer monsoon variability reflected by $\mathrm{d} 180$ in tree-ring from Tibetan junipers, Geophys. Res. Lett. 38, L03701.

Guangliang, H., E. Chongyi, and L. Xiangjun (2013), Reconstruction of integrated temperature series of the past 2000 years on the Tibetan Plateau with 10-year intervals, Theor. Appl. Climatol. 113, 259-269.

Guo, D., and H. Wang (2012), The significant climate warming in the northern Tibetan Plateau and its possible causes, Int. J. Climatol. 32, 1775-1781.

Hagemann S., and L. Dümenil Gates (2003), Improving a subgrid runoff parameterization scheme for climate models by the use of high resolution data derived from satellite observations, Climate Dyn. 21, 349--359.

Hahn, D.G., and S. Manabe (1975), The role of mountains in the South Asian monsoon circulation, J. Atmos. Sci. 32, 1515-1541. 
Harrison, S.P., P.J. Bartlein, S. Brewer, I.C. Prentice, M. Boyd, I. Hessler, K. Holmgren, K. Itzumi, and K. Willis (2014), Climate model benchmarking with glacial and midHolocene climates, Clim. Dyn. 43, 671-688.

Insel, N., C.J. Poulsen, T.A. Ehlers, and C. Sturm (2012), Response of meteoric d18O to surface uplift - Implications for Cenouoic Andean Plateau growth, Earth Planet. Sci. Lett. 317-318, 262-272.

IPCC (2013), Climate Change 2013, The Physical Science Basis, Working Group I Contribution to the Fifth Assessment Report of the Intergovernmental Panel on Climate Change, Cambridge Univ. Press, Cambridge, 1535 pp.

Jacob D. (2001), A note to the simulation of the annual and interannual variability of the water budget over the Baltic Sea drainage basin, Meteorol. Atmos. Phys. 77, $61--74$.

Ju, L. H. Wang, and D. Jiang (2007), Simulation of the Last Glacial Maximum climate over East Asia with a regional climate model nested in a general circulation model, Palaeogeography, Palaeoclimatology, Palaeoecology 248, 376-390.

Jungclaus, J.H., N. Keenlyside, M. Botzet, H. Haak, J.J. Öuo, M. Latif, J. Marotzke, U. Mikolajewicz, and E. Roeckner (2006), Ocean circulation and tropical variability in the coupled model ECHAM5/MPI-OM, J. Climate 19, 3952-3972.

Kalnay E., M. Kanamitsu, R. Kistler, W. Collins, D. Deaven, L.S. Gandin, M. Iredell, S. Saha, G. White, J. Woolen, Y. Zhu, M. Chelliah, W. Ebisuzaki, W. Higgins, J. Janowiak, K.C. Mo, C. Ropelewsky, J. Wang, A. Leetma, R. Reynolds, R. Jenne and D. Joseph (1996), The NCEP/NCAR 40-year Reanalysis Project, Bull Amer Meteor Soc 77, 437-471.

Kitoh, A., T. Motoi, and O. Arakawa (2010), Climate modelling study on mountain uplift and Asian monsoon evolution, Geol. Soc. London, Special Publ. 342, 293-301. 
Kutzbach, J.E., P.J. Guetter, W.F. Ruddiman, and W.L. Prell (1989), Sensitivity of climate to Quaternary Cenozoic uplift in southern Asia and the American West: Numerical experiments, J. Geophys. Res. 94, 18393-18407.

Kutzbach, J.E., W.L. Prell, and W.F. Ruddiman (1993), Sensitivity of Eurasian climate to surface uplift of the Tibetan Plateau, J. Geology 101, 177-190.

Le Pichon, X., M. Fournier, and L. Jolivet (1992), Kinematics, topography, shortening, and extrusion in the India-Eurasia collision, Tectonics 11, 1085-1098.

Li, J., T.A. Ehlers, S. Mutz, C. Steger, H. Paeth, M. Werner, C.J. Poulsen, R. Feng (2016), Modern precipitation d180 and trajectory analysis over the Himalaya-Tibet orogen from ECHAM5-wiso simulations, J. Geophys. Res., under revision.

Li, J., T.A. Ehlers, M. Werner, S. Mutz, C. Steger, and H. Paeth (2016), Quaternary Quaternary climate, precipitation d180, and Indian Monsoon variations over the Tibetan Plateau, Earth Planet. Sci. Lett., under revision.

Liebke, U., E. Appel, L. Ding, and Q. Zhang (2013), Age constraints on the India-Asia collision derived from secondary remanences of Tethyan Himalayan sediments from the Tingri area, J. Asian Earth Sci. 62, 329-340.

Liu, Y., J. He, W. Li, and L. Chen (2008a), MM5 simulations of the China regional climate during the LGM. I: Influence of CO2 and Earth orbit change, Acta Meteorol. Sinica 22, 8-21.

Liu, Y., J. He, W. Li, and L. Chen (2008b), MM5 simulations of the China regional climate during the LGM. I: Influence of change of land area, vegetation, and largescale circulation background, Acta Meteorol. Sinica 22, 22-30.

Lorenz, S., and G. Lohmann (2004), Acceleration technique for Milankowitch type forcing in a coupled atmosphere-ocean circulation model: method and application for the Holocene, Clim. Dyn. 23, 727-743. 
Ma, D., W. Boos, and Z. Kuang (2014), Effects of orography and surface heat fluxes on the South Asian summer monsoon, J. Climate 27, 6647-6659.

Mannig, B., M. Müller, E. Starke, C. Merkenschlager, W. Mao, X. Zhi, R. Podzun, D. Jacob, and H. Paeth (2013), Dynamical downscaling of climate change in Central Asia, Global Planet. Change 110, 26-39.

Maussion F., D. Scherer, T. Mölg, E. Collier, J. Curio and R. Finkelnburg (2014), Precipitation seasonality and variability over the Tibetan Plateau as resolved by the High Asia Reanalysis, J. Climate 27, 1910-1927.

Mironov, D., E. Heise, E. Kourzeneva, B. Ritter, N. Schneider, and A. Terzhevik (2010), Implementation of the lake parameterization scheme Flake into the numerical weather prediction model COSMO, Boreal Environ. Res. 15, 218-230.

Mischke, S., B. Wünnemann, and E. Appel (2013), Proxies for Quarternary monsoon reconstruction on the Tibetan Plateau, Quart. International 313-314, 1-2.

Mitchell T.D., and P.D. Jones (2005), An improved method of constructing a database of monthly climate observations and associated high-resolution grids, Int. J. Climatol. 25, 693--712.

Molnar, P. (2005), Mio-Pliocene growth of the Tibetan Plateau and evolution of east African climate, Palaeontol. Electronica 8, 1-23.

Molnar, P., and B. Rajagopalan (2012), Quaternary Miocene upward and outward growth of eastern Tibet and decreasing monsoon rainfall over the northwestern Indian subcontinent since $\sim 10$ MA, Gephys. Res. Lett. 39, L09702.

Mutz, S.G., T.A. Ehlers, J. Li, C. Steger, H. Paeth, M. Werner, and C.J. Poulsen (2016), Precipitation d180 over the Himalaya-Tibet orogen from ECHAM5-wiso slmulations: Statistical analysis of temperature, topography, and precipitation. J. Geophys. Res.,121, 9278-9300, doi:10.1002/2016JD024856. 
Netzel P., and T. Stepinski (2016), On using a clustering approach for global climate classification, J. Climate, doi:10.1175/JCLI-D-15-0640.1.

Paeth, H. (2011), Postprocessing of simulated precipitation for impact studies in West Africa - Part I: model output statistics for monthly data, Climate Dyn. 36, 1321--1336. change in tropical Africa under greenhouse forcing and land-use changes, J. Climate 22, 114--132.

Paeth, H., K. Born, R. Podzun, and D. Jacob (2005), Regional dynamical downscaling

Park, H.-S., J.C.H. Chiang, and S. Bordoni (2012), The mechanical impact of the Meteorolog. Z. 14, 349--367.

Paeth, H., N.M. Hall, M.A. Gaertner, M. Dominguez Alonso, S. Moumouni, J. Polcher, P.M. Ruti, A.H. Fink, M. Gosset, T. Lebel, A.T. Gaye, D.P. Rowell, W. MoufoumaOkia, D. Jacob, B. Rockel, F. Giorgi, and M. Rummukainen (2011), Progress in regional downscaling of West African precipitation, Atmos. Sci. Let. 12, 75--82. Tibetan Plateau on the seasonal evolution of the South Asian monsoon, J. Climate 25, 2394-2407.

Paxian, A., and 12 co-authors (2015), Bias reduction in decadal predictions of West African monsoon rainfall using regional climate models, J. Geophys. Res., doi: 10.1029/2015JD024143.

Polanski, S., A. Rinke, and K. Dethloff (2012), Simulation and comparison between mid-Holocene and preindustrial Indian summer monsoon circulation using a regional climate model, Open Atmos. Sci. J. 6, 42-48.

Prell, W.L., and J.E. Kutzbach (1992), Sensitivity of the Indian monsoon to forcing parameters and implications for its evolution, Nature 360, 647-652. 
Clim. Past Discuss., https://doi.org/10.5194/cp-2017-111

Manuscript under review for journal Clim. Past

Discussion started: 17 October 2017

(c) Author(s) 2017. CC BY 4.0 License.

Rayner, N.A., E.B. Horton, D.E. Parker, C.K. Folland, and R.B. Hackett (1996), Version 2.2 of the global sea ice and sea surface temperature data set, 1903-1994, Clim Res. Tech. Note CRTN74, Hadley Centre, Bracknell.

Ruddiman, W.F. (2014), Earth's climate. Past and Future, W.H. Freeman and Company, New York.

Saeed; F., S. Hagemann, and D. Jacob (2011), A framework for the evaluation of the South Asian summer monsoon in a regional climate model applied to REMO, Int.. J. Climatol. 32, 430-440.

Saraswat, R., R. Nigam, and T. Correge (2013), A glimpse of the Quaternary monsoon history from India and adjoining seas, Palaeogeography, Palaeclimatology, Palaeoecology 397, 1-6.

Sein, D.V., U. Mikolajewicz, M. Gröger, I. Fast, W. Cabos, J.G. Pinto, S. Hagemann, T. Semmler, A. Izquierdo, and D. Jacob (2015), Regionally coupled atmosphereocean-sea ice-marine biogeochemistry model ROM: 1. Description and validation, J. Adv. Model. Earth Syst. 7, 268-304.

Song, J.-H., H.-S. Kang, Y.-H. Byun, and S.-Y. Hong (2009), Effects oft he Tibetan Plateau on the Asian summer monsoon: a numerical case study using a regional climate model, Int. J. Climatol. 30, 743-759.

Su, F., X. Duan, D. Chen, and L. Cuo (2013), Evaluation of the global climate models in the CMIP5 over the Tibetan Plateau, J. Climate 26, 3187-3208.

Tang, H., A. Micheels, J. Eronen, B. Ahrens, and M. Fortelius (2013a), Asynchronous responses of East Asian and Indian summer monsoons to mountain uplift shown by regional climate modeling experiments, Clim. Dyn. 40, 1531-1549.

Tang, H., J. Eronen, A. Micheels, and B. Ahrens (2013b): Strong interannual variation of the Indian summer monsoon in the Quaternary Miocene, Clim. Dyn. 41, 135-153. 
Uppala, S., and 45 co-authors (2005), The ERA-40 re-analysis, Q. J. R. Meteorol. Soc.

$880 \quad 131,2961-3012$.

Wang, T., D. Hong, B. Jahn, Y. Tong, Y. Wang, B. Han, and X. Wang (2006), Timing, petrogenesis, and setting of Paleozoic synorogenic intrusions from the Altai

Werner, M., P.M. Langebroek, T. Carlsen, M. Herold, and G. Lohmann (2011), Stable water isotopes in the ECHAM5 general circulation model: Toward high-resolution isotope modeling on a global scale, J. Geophys. Res. 116, doi:10.1029/2011 JD015681.

Wilks, D.S. (2006), Statistical methods in the atmospheric sciences, Academic Press, Amsterdam, 627pp.

Wu, G., Y. Liu, B. Dong, X. Liang, A. Duan, Q. Bao, and J. Yu (2012): Revisiting Asian

Yang, T., X. Hao, Q. Shao, C.-Y. Xu, C. Zhao, X. Chen, and W. Wang (2012), Multi-

896 Tibetan Plateau in the $21^{\text {st }}$ century, Global Planet. Change 80-81, 1-13.

897 Zhang, R., D. Jiang, Z. Zhang, and E. Yu (2014), The impact of regional uplift oft he 898 Tibetan Plateau on the Asian monsoon climate, Palaeogeography, 899 Palaeoclimatology, Palaeoecology 417, 137-150. 
Clim. Past Discuss., https://doi.org/10.5194/cp-2017-111

Manuscript under review for journal Clim. Past

Discussion started: 17 October 2017

(c) Author(s) 2017. CC BY 4.0 License.

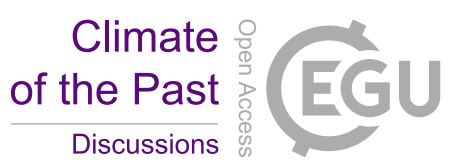

(c) (1)

900 Zheng, Y.Q., G. Yu, S.M. Wang, B. Xue, D.Q. Zhuo, X.M. Zeng, and H.Q. Liu (2004),

901 Simulation of paleoclimate over East Asia at $6 \mathrm{ka} \mathrm{BP}$ and $21 \mathrm{ka}$ BP by a regional

902 climate model, Clim. Dyn. 23, 513-529.

903 
Clim. Past Discuss., https://doi.org/10.5194/cp-2017-111

Manuscript under review for journal Clim. Past

Discussion started: 17 October 2017

(c) Author(s) 2017. CC BY 4.0 License.

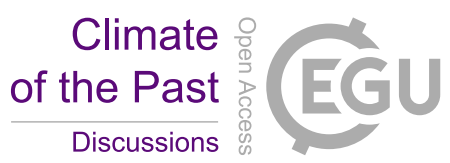

904

Figures

905

906

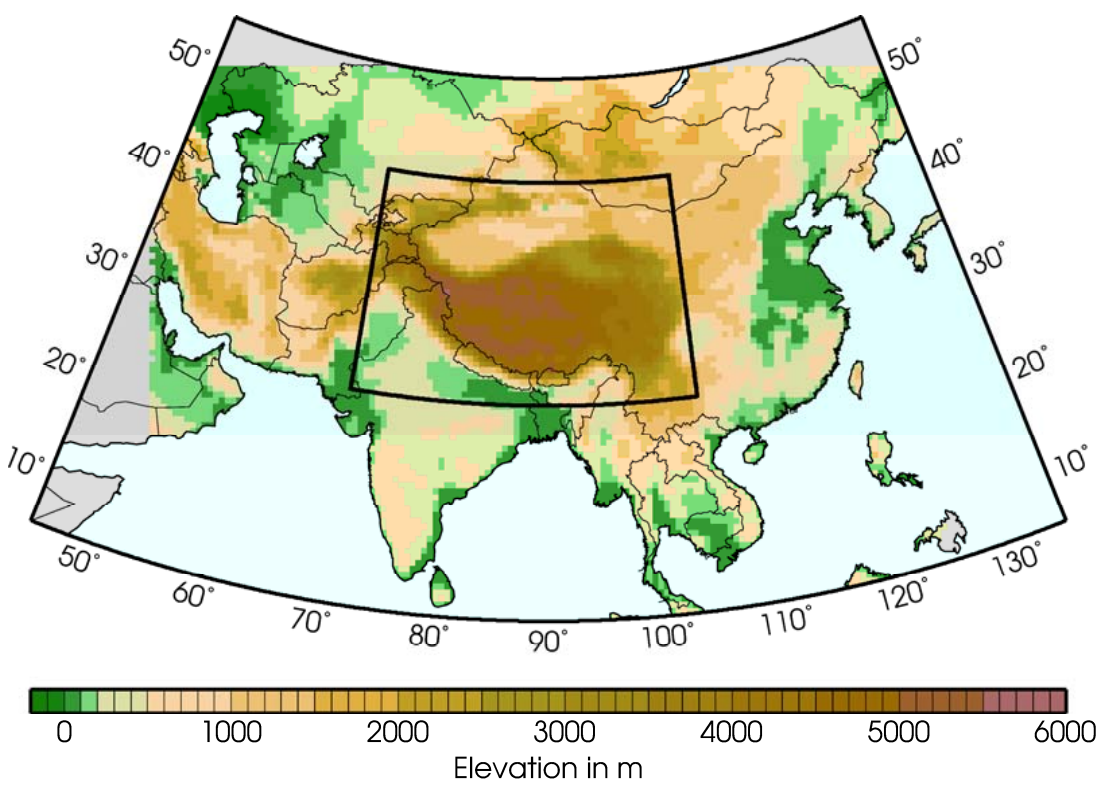

908

909 Figure 1: Domain for the dynamical downscaling with REMO (outer region) and for the

910 cluster analysis centered over the Tibetan Plateau (inner region). 
Clim. Past Discuss., https://doi.org/10.5194/cp-2017-111

Manuscript under review for journal Clim. Past

Discussion started: 17 October 2017

(c) Author(s) 2017. CC BY 4.0 License.
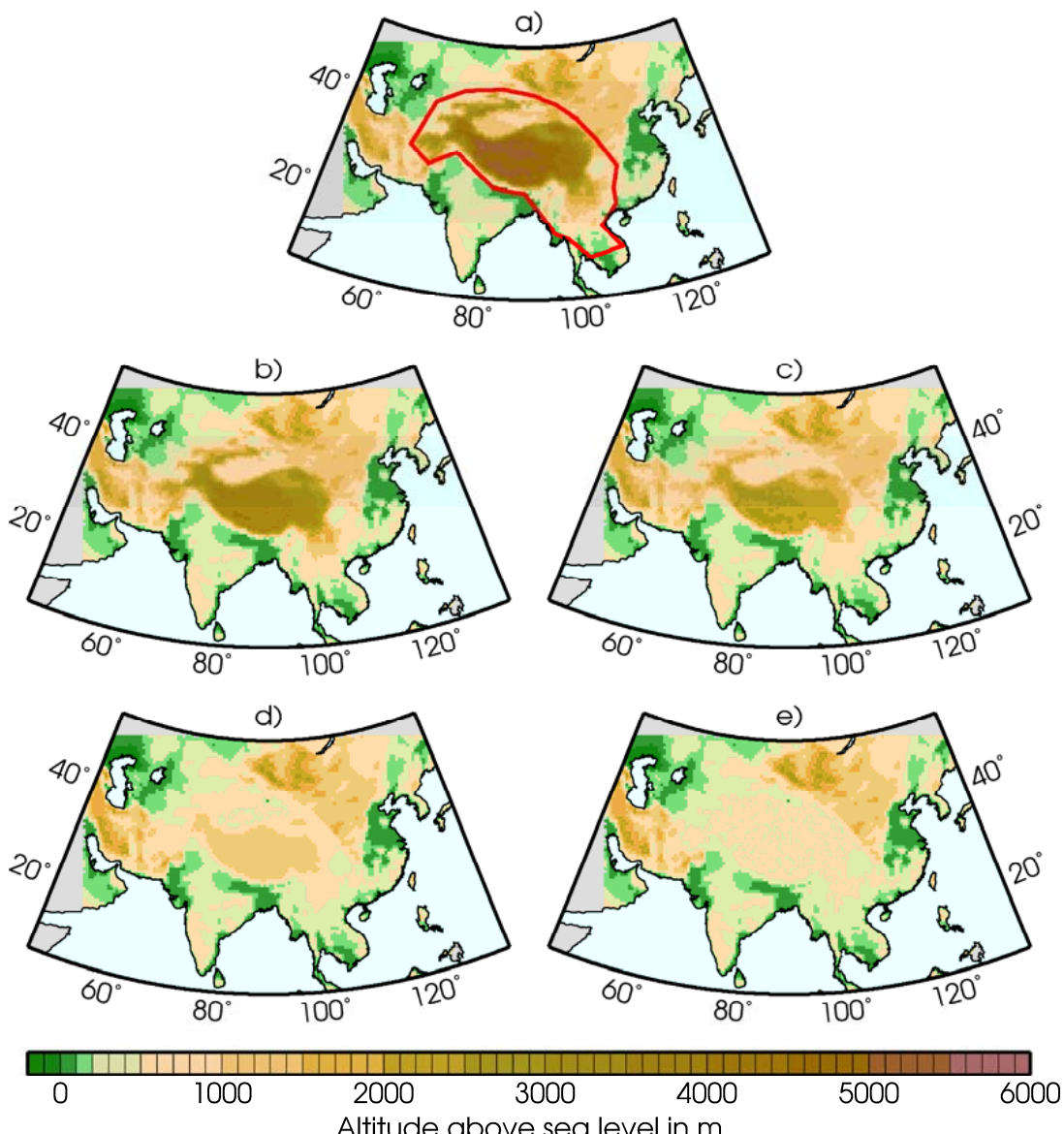

915 Figure 2: Topography over Central Asia for the control run with present-day elevation

916 (a) and the stepwise reduction to $75 \%$ (b), $50 \%$ (c), $25 \%$ (d) and complete leveling (e) 917 compared with present-day elevation. 
Clim. Past Discuss., https://doi.org/10.5194/cp-2017-111

Manuscript under review for journal Clim. Past

Discussion started: 17 October 2017

(c) Author(s) 2017. CC BY 4.0 License.

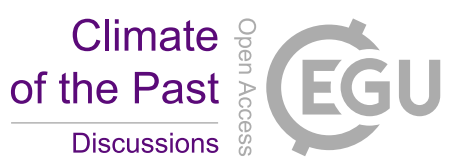

(c) (i)

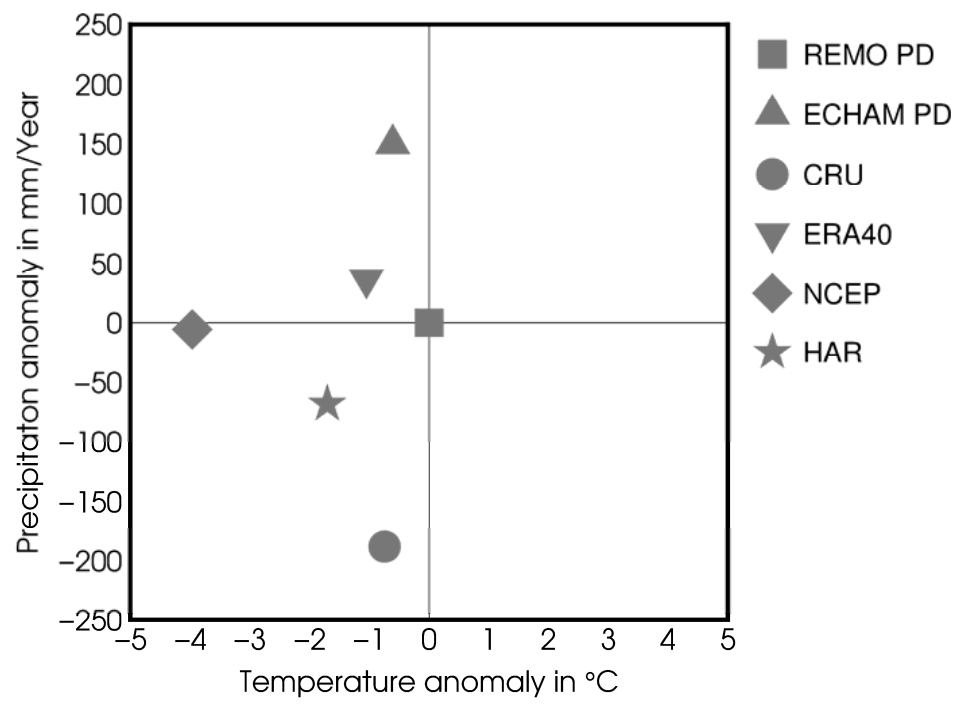

921 Figure 3: Comparison of mean temperature and precipitation averaged over the cluster

922 domain (cf. Fig. 1) and the time period 1971-2000 from the regional climate model

923 REMO (PD = present-day), the driving global climate model ECHAM, the regional re-

924 analysis HAR, the global reanalysis NCEP, and the CRU observational data set.

925 
Clim. Past Discuss., https://doi.org/10.5194/cp-2017-111

Manuscript under review for journal Clim. Past

Discussion started: 17 October 2017

(c) Author(s) 2017. CC BY 4.0 License.
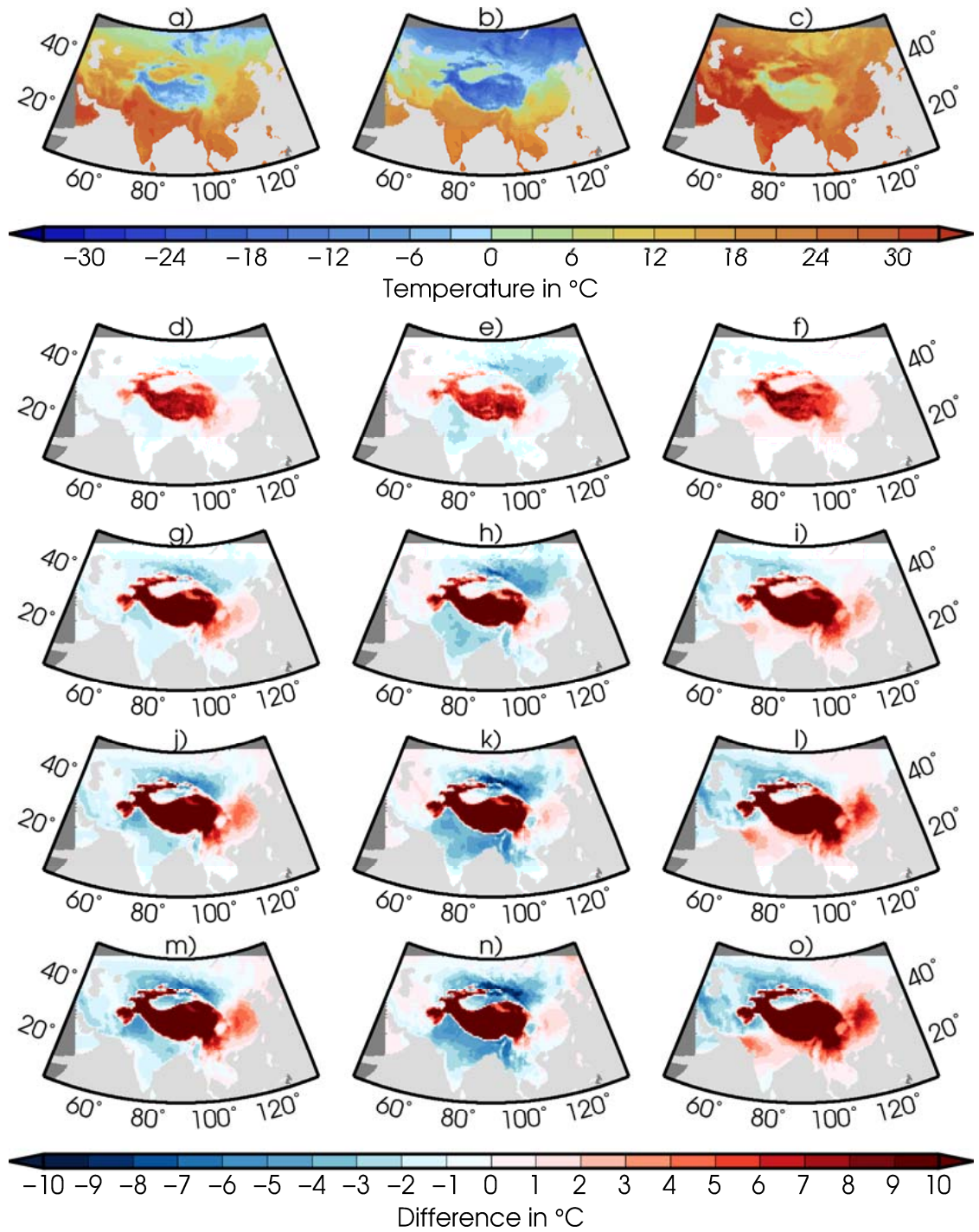

Figure 4: Near-surface temperature averaged over the control period 1971-2000 (top row) for annual means (left column), winter means (middle column) and summer means (right column) as well as temperature changes due to a stepwise reduction of elevation (d-o) from T075 (upper panels) to T000 (lower panels). 
Clim. Past Discuss., https://doi.org/10.5194/cp-2017-111

Manuscript under review for journal Clim. Past

Discussion started: 17 October 2017

(c) Author(s) 2017. CC BY 4.0 License.

(c) (1)
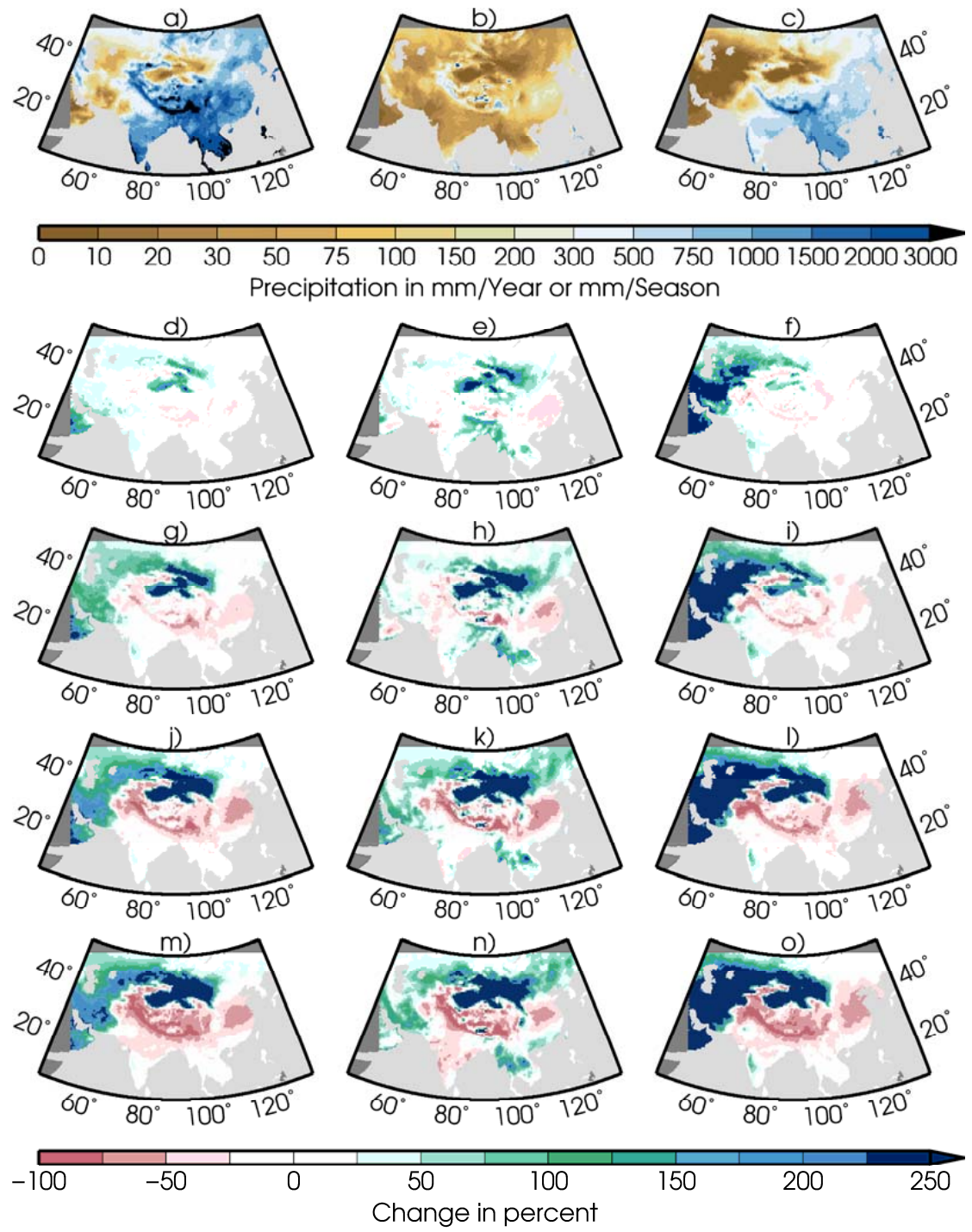

Figure 5: Same as Fig. 4 but for total precipitation. 
Clim. Past Discuss., https://doi.org/10.5194/cp-2017-111

Manuscript under review for journal Clim. Past

Discussion started: 17 October 2017

(c) Author(s) 2017. CC BY 4.0 License.

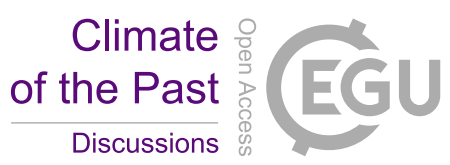

(c) (i)
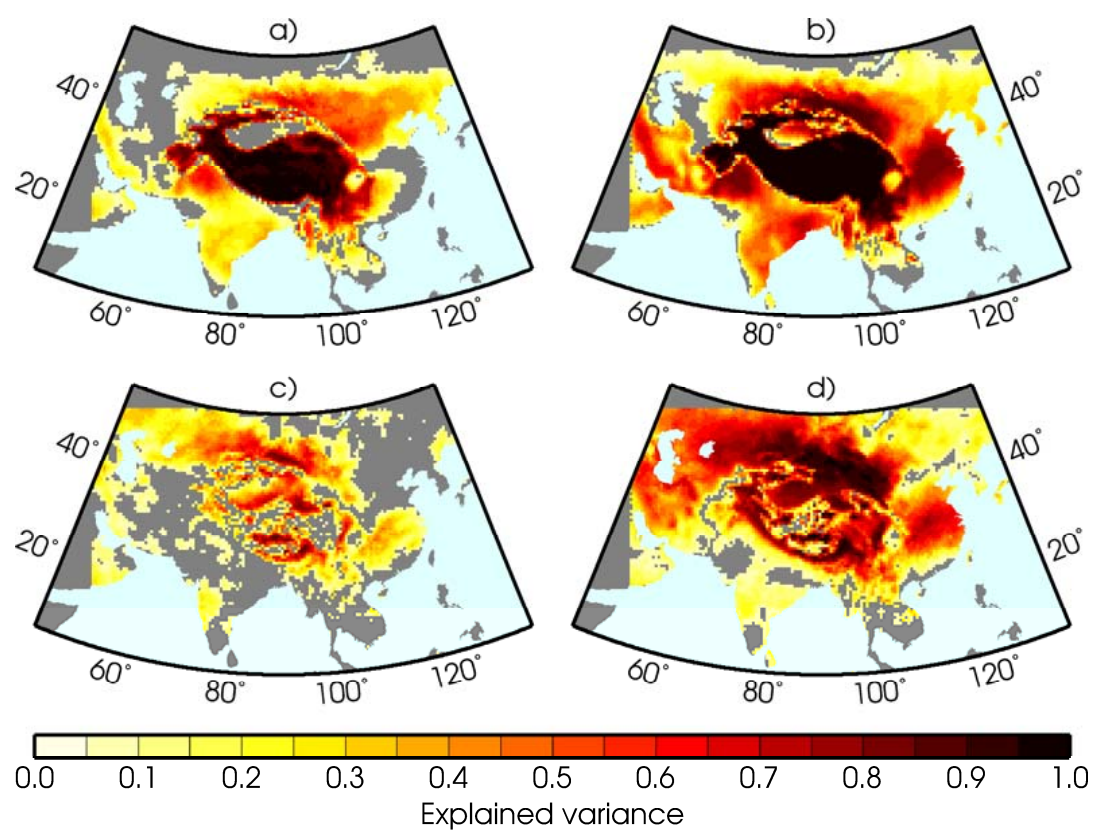

941

942 Figure 6: Portion of variance explained by the uplift of the Tibetan Plateau as inferred

943 from a one-way analysis of variance for near-surface temperature (top panels) and

944 total precipitation (bottom panels) assessed between the T100 and T075 experiments

945 (left column) and between all uplift experiments T100 - T000 (right column). Only

946 values significant at the $5 \%$ level are plotted. 
Clim. Past Discuss., https://doi.org/10.5194/cp-2017-111

Manuscript under review for journal Clim. Past

Discussion started: 17 October 2017

(c) Author(s) 2017. CC BY 4.0 License.
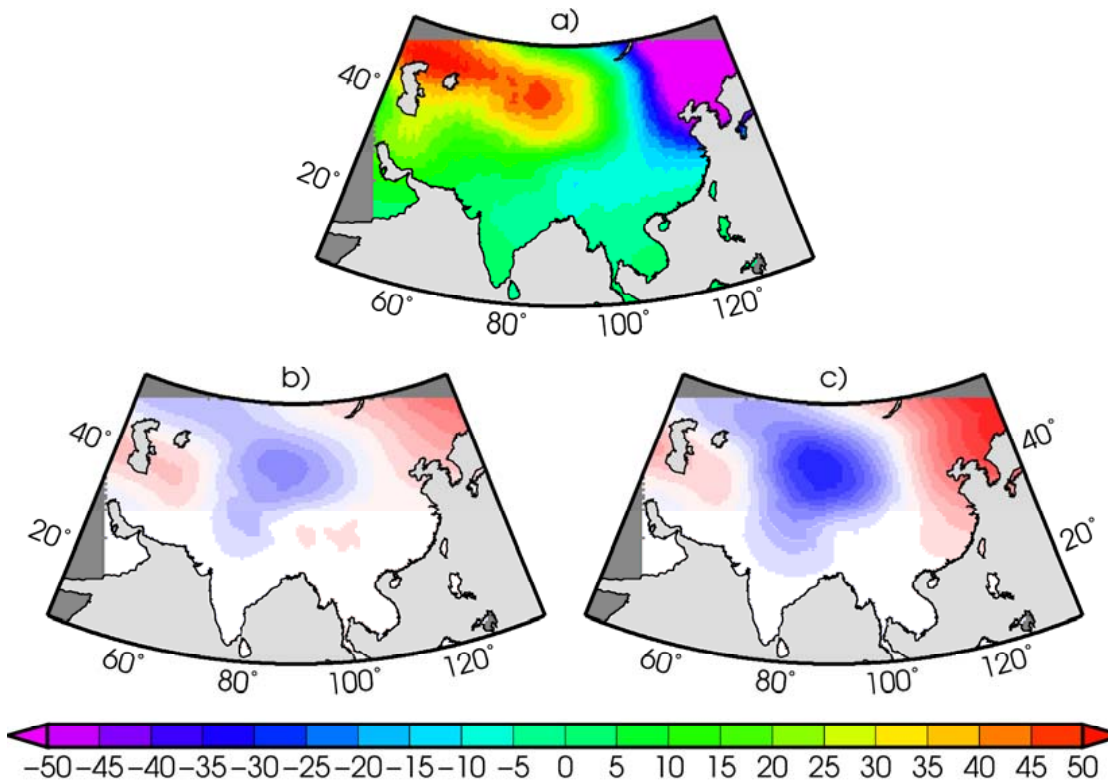

Zonal anomaly of geopotential height in gpm

950 Figure 7: Anomalies of $500 \mathrm{hPa}$ geopotential height from the zonal mean averaged

951 over the control period 1971-2000 (a) and changes due to a stepwise reduction of

952 elevation in the T050 (b) and T000 (c) experiments. 
Clim. Past Discuss., https://doi.org/10.5194/cp-2017-111

Manuscript under review for journal Clim. Past

Discussion started: 17 October 2017

(c) Author(s) 2017. CC BY 4.0 License.

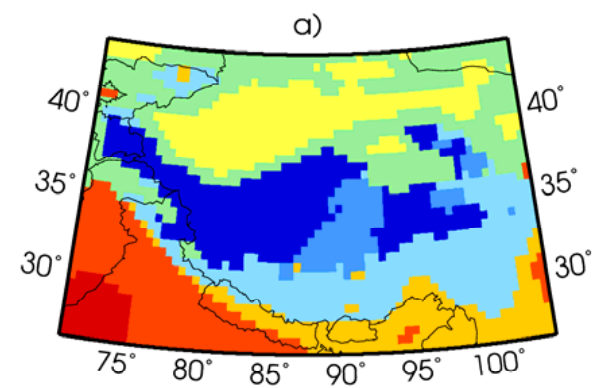

b)

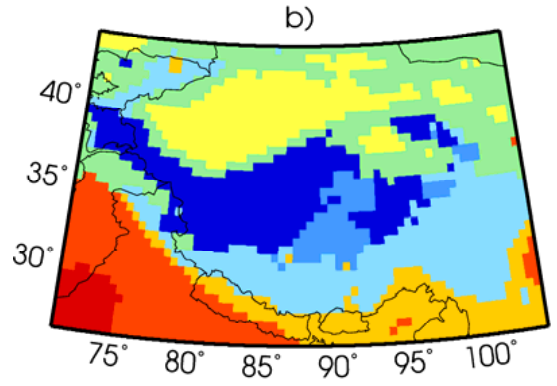

d)
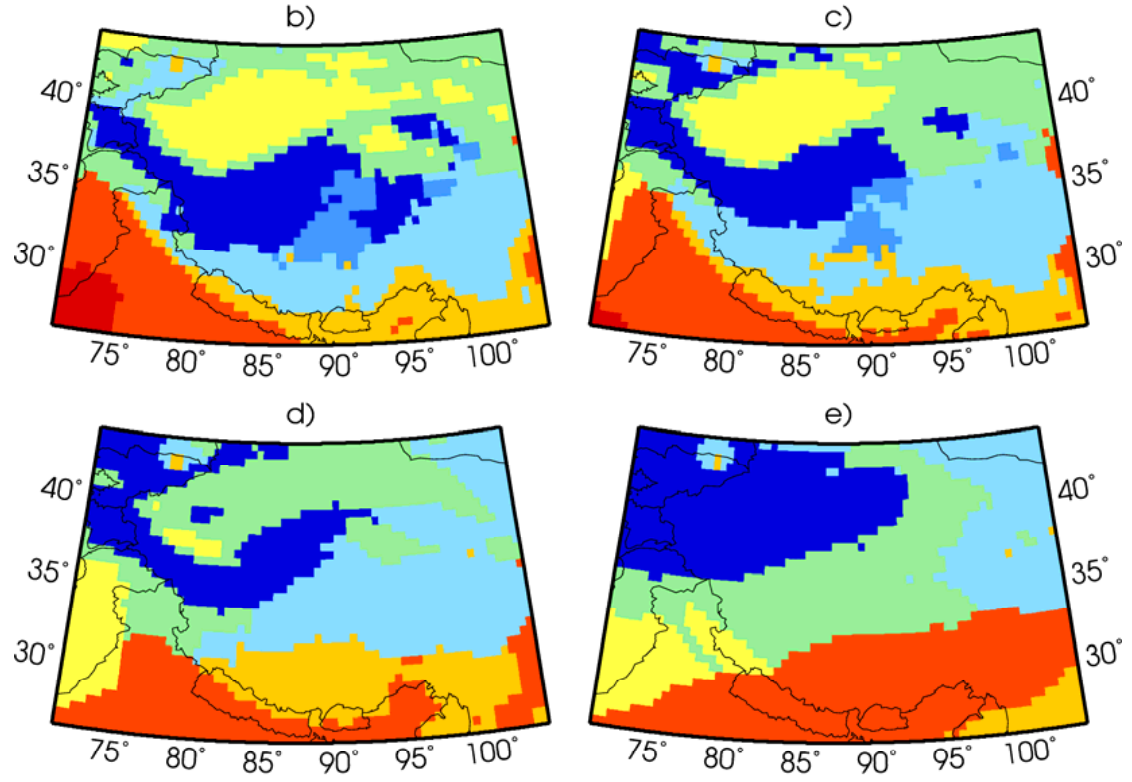

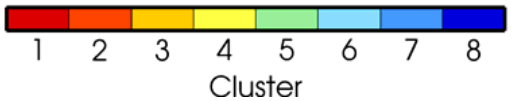

Figure 8: Results of the cluster analysis prescribing 8 clusters in the Tibetan Plateau 
Clim. Past Discuss., https://doi.org/10.5194/cp-2017-111

Manuscript under review for journal Clim. Past

Discussion started: 17 October 2017

(c) Author(s) 2017. CC BY 4.0 License.
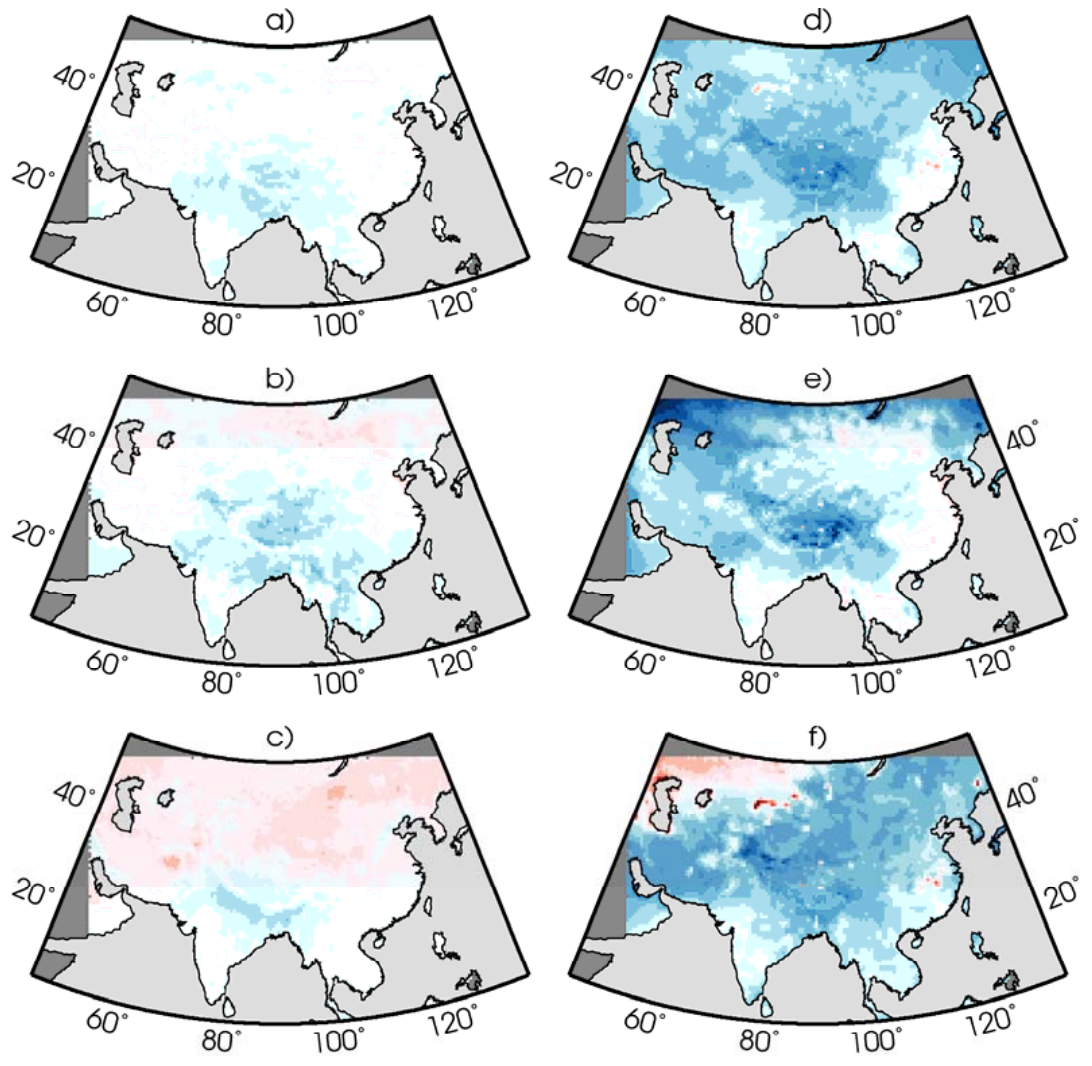

Figure 9: Changes in near-surface temperature for annual means (top row), winter means (middle row) and summer means (bottom row) as simulated by the MH (left column) and LGM (right column) experiment compared with the 1980-1989 control period. 
Clim. Past Discuss., https://doi.org/10.5194/cp-2017-111

Manuscript under review for journal Clim. Past

Discussion started: 17 October 2017

(c) Author(s) 2017. CC BY 4.0 License.

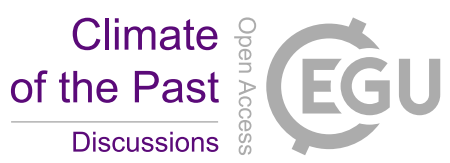

(c) $\underset{0}{(1)}$
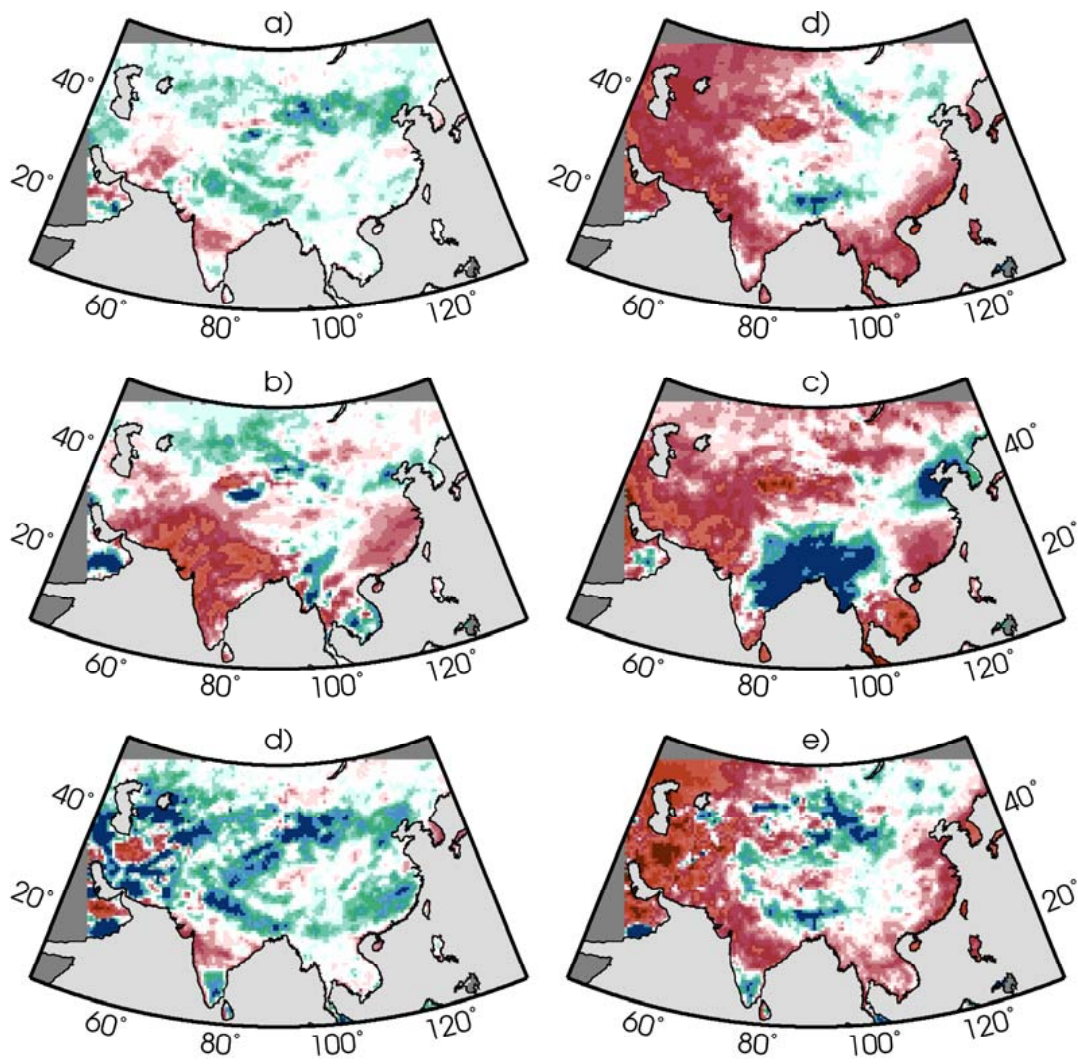

968

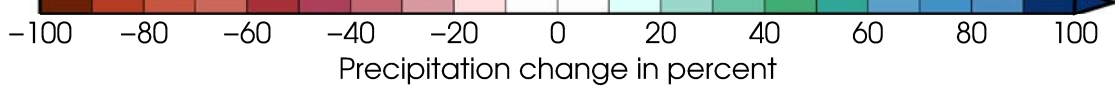

969

970 Figure 10: Same as Fig. 9 but for total precipitation. 
Clim. Past Discuss., https://doi.org/10.5194/cp-2017-111

Manuscript under review for journal Clim. Past

Discussion started: 17 October 2017

(c) Author(s) 2017. CC BY 4.0 License.

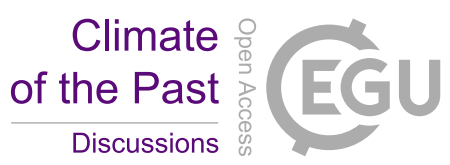

(c) (i)
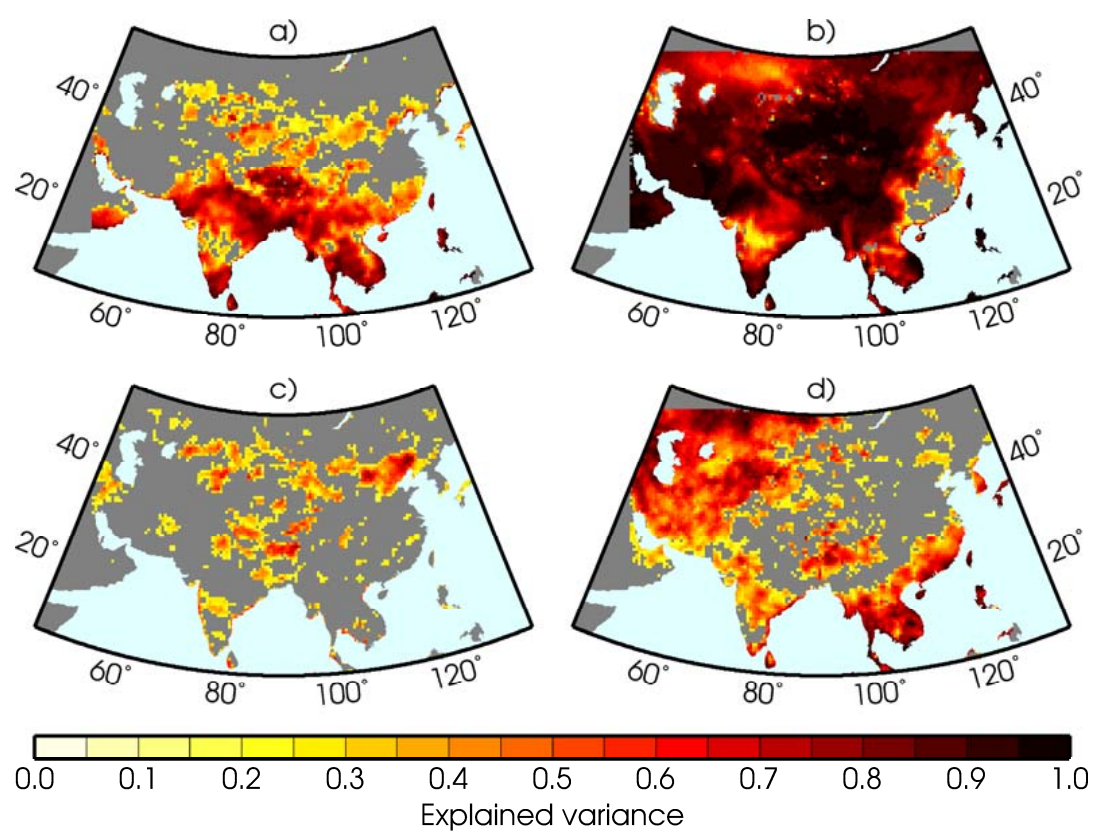

974 Figure 11: Portion of variance explained by the MH (left column) and LGM (right col-

975 umn) experiment as inferred from a one-way analysis of variance for near-surface tem-

976 perature (top panels) and total precipitation (bottom panels). Only values significant at

977 the $5 \%$ level are plotted. 
Clim. Past Discuss., https://doi.org/10.5194/cp-2017-111

Manuscript under review for journal Clim. Past

Discussion started: 17 October 2017

(c) Author(s) 2017. CC BY 4.0 License.
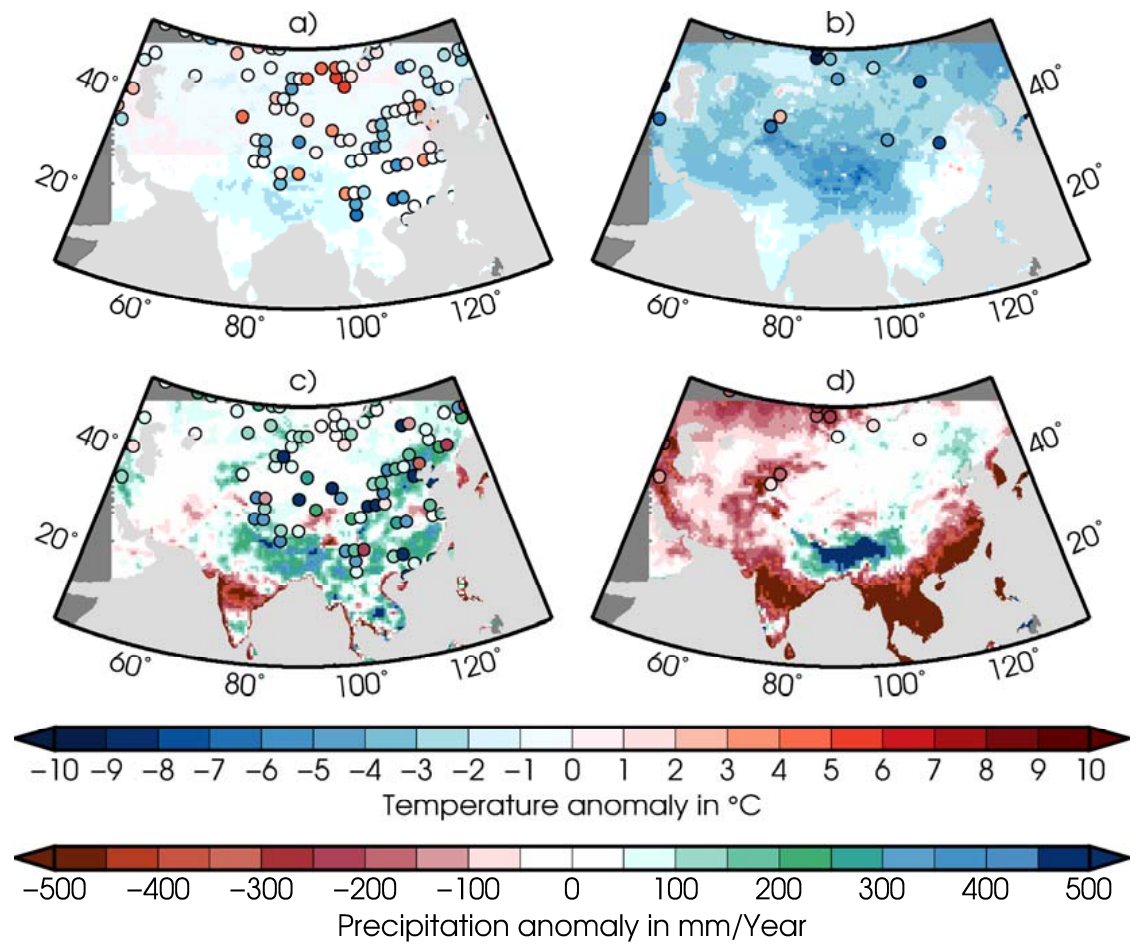

Figure 12: Comparison of simulated mean annual temperature (top row) and total pre-

cipitation (bottom row) changes in the MH (left column) and LGM (right column) period pollen analysis (Bartlein et al. 2011). 
Clim. Past Discuss., https://doi.org/10.5194/cp-2017-111

Manuscript under review for journal Clim. Past

Discussion started: 17 October 2017

(c) Author(s) 2017. CC BY 4.0 License.

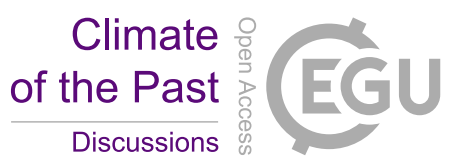

986
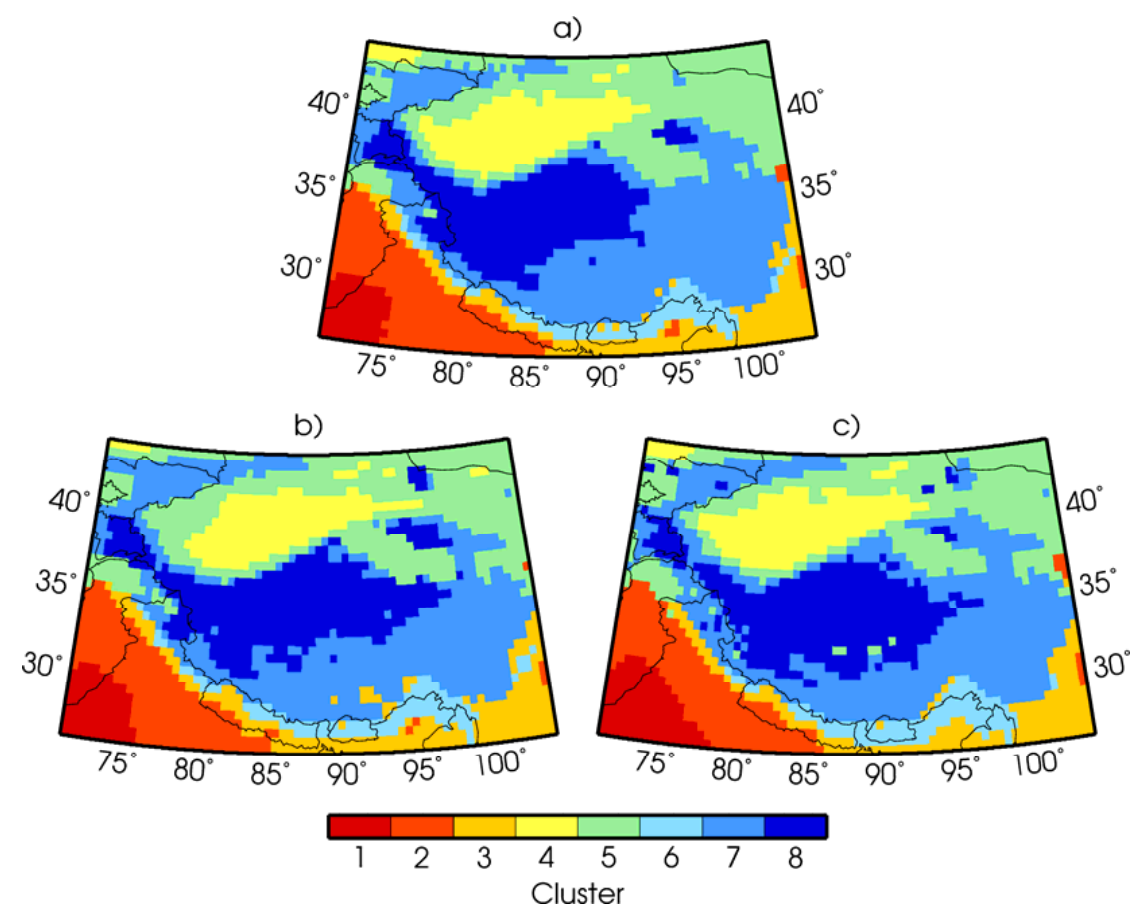

987

988

989 Figure 13: Results of the cluster analysis prescribing 8 clusters in the Tibetan Plateau

990 region for the control period 1980-1989 (a) and projection of the MH (b) and LGM (c)

991 experiments onto the same centroids from the control period.

992 
Clim. Past Discuss., https://doi.org/10.5194/cp-2017-111

Climate

Manuscript under review for journal Clim. Past

Discussion started: 17 October 2017

(c) Author(s) 2017. CC BY 4.0 License.
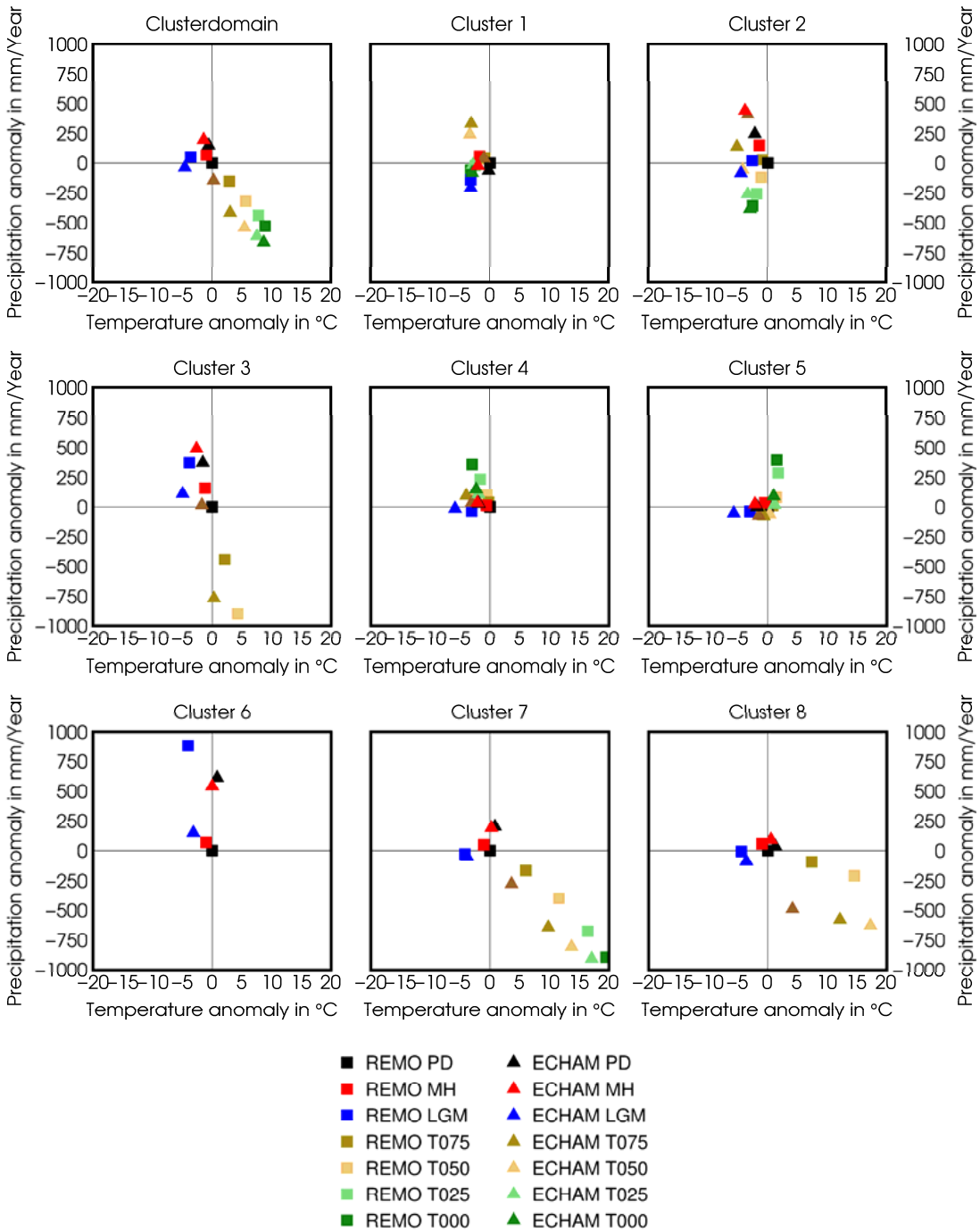

994 Figure 14: Synthesis of changes in annual mean near-surface temperature ( $\mathrm{x}$-axis) and

995 total precipitation (y-axis) averaged over the entire cluster domain (top left) and over

996 the individual 8 cluster regions (remaining panels) from the uplift, MH and LGM exper-

997 iments compared with the respective control periods, once for the regional climate

model REMO and once for the driving global climate model ECHAM. 